\title{
An Empirical Framework for Large-Scale Policy Analysis, with an Application to School Finance Reform in Michigan
}

\author{
Maria Marta Ferreyra \\ Tepper School of Business \\ Carnegie Mellon University
}

August 16, 2007*

\begin{abstract}
In this paper I develop an empirical framework for the analysis of large-scale policies, and apply it to study the effects of Michigan's 1994 school finance reform on the Detroit metropolitan area. The framework includes estimating a general equilibrium model of multiple jurisdictions with data before the reform, predicting the post-reform equilibrium, and comparing this prediction with postreform data to validate the model. According to my analysis, the Michigan reform had little impact on household demographics or school quality in Detroit. The alternative school funding policies analyzed here do not seem to affect school quality much either. (JEL C52, I22, H73)
\end{abstract}

\footnotetext{
* I thank the Berkman Faculty Development Fund at Carnegie Mellon University for financial support. I also thank Julie Berry Cullen and Susanna Loeb for providing me with data on pass rates for Michigan. Mary Ann Cleary, Jeff Guilfoyle, Andrew Lockwood, and Glenda Rader from the government of the state of Michigan answered many of my questions on Proposal A. I am indebted to Dennis Epple, George-Levy Gayle, Holger Sieg, and Fallaw Sowell for valuable conversations, and to participants at the 2004 summer workshop at the Federal Reserve of Cleveland for comments on an earlier version of this paper. I thank Jeff Reminga for assistance with the technical aspects of this project, Bill Buckingham from the Applied Population Lab at University of Wisconsin-Madison for Arc GIS support, and Surendra Bagde for research assistance. All errors are mine.
} 


\section{Introduction}

Although typically aiming at specific effects, large-scale policies can often trigger other, general equilibrium effects as well. Thus, a comprehensive evaluation of these policies requires a general equilibrium framework. Furthermore, it is desirable that the framework serve not only for the analysis of actual but also of counterfactual policies, particularly in light of the potentially high cost and far-reaching consequences of large-scale policies. An important issue, however, is how to develop a reliable framework. Whereas the estimation of a model provides evidence on its fit to the data, perhaps more critical evidence comes from the model's ability to fit out-of-sample data.

In this paper I develop an empirical framework for the analysis of large-scale policies that relies on a general equilibrium model, allows for counterfactual analysis and conducts model validation, and apply it to study the effects of the Michigan school finance reform on the Detroit metropolitan area. Concerns about the equity and adequacy of public school funding have led most states over the last thirty years to overhaul their systems of public school funding. Thus, in 1994 the state of Michigan implemented a school finance reform. This largely unexpected reform, known as Proposal $\mathrm{A},{ }^{1}$ shifted the funding of public schools away from local school districts onto the state. School districts are no longer able to determine their property tax rates and hence their revenues; instead, they receive from the state a per-student allowance ("foundation allowance”). This revenue scheme increased revenue for low-revenue districts, and capped revenues for high-revenue districts in an attempt to reduce revenue variation. Proposal A also implemented a tax reform by which property tax rates on owner-occupied housing were reduced from a state

\footnotetext{
${ }^{1}$ See Adonizio et al (1995) and Cullen and Loeb (2004) for further details on the reform.
} 
average of 3.4 percent to a statewide uniform tax of 0.6 percent on all property, and state sales taxes were concomitantly increased.

In metropolitan areas where households choose locations and schools jointly, a reform such as Proposal A may alter not only school revenues and property taxes, but also households' choices, housing prices, and public schools’ qualities. For instance, districts that benefit from lower property taxes and higher revenues may experience an increase in property values and an improvement in local public school quality. They may also attract residents from other districts, which would further alter housing prices.

I capture these effects through an equilibrium model of multiple jurisdictions and household residential and school choice, and estimate the structural parameters using 1990 data for the Detroit metropolitan area. I use the parameter estimates to simulate the 2000 equilibrium accounting for a number of changes in the metropolitan area over the decade including the school finance reform - and then compare the predictions with the 2000 data. The model provides a reasonable fit for the in-sample data used for estimation and the outof-sample data used for model validation, which lends credibility to the policy analysis.

The existing literature on school funding reform encompasses two main types of studies. First, some researchers have investigated the equilibrium effects of school finance reform using calibrated models. ${ }^{2}$ I build on this body of research by estimating an equilibrium model based on Ferreyra (2007) and Nechyba (1999), which allows me to study the model's fit to the data, the identification of the structural parameters, and the sensitivity of the parameter estimates to various features of the model. Although scholars have recently used their parameter estimates from equilibrium models for policy

\footnotetext{
${ }^{2}$ See, for instance, Nechyba (2004) and Fernandez and Rogerson (2003).
} 
simulations, ${ }^{3}$ no direct evidence exists on whether the models' out-of-sample predictions are correct because the simulated policies have never been implemented in large scale. My paper, in contrast, overcomes this obstacle. Second, other researchers have conducted empirical investigations on school finance reform. Although they have mostly focused on one type of effect, ${ }^{4}$ some have studied equilibrium effects ${ }^{5}$ yet from a reduced-form perspective. Not only does my framework lead to estimates for Proposal A's effects that are broadly consistent with those from other studies, but it also allows for model validation and the investigation of counterfactual policies. Furthermore, the type of analysis conducted here is of interest to other metropolitan areas as well, given the ongoing activity in the school finance arena. ${ }^{6}$

A test of model validity that relies on out-of-sample data is more meaningful the greater the differences between the in-sample and out-of-sample data. Thus, researchers have exploited opportunities for model validation that arise because of differences over time due to policy changes, or at one point in time because of treatment assignment or policy variation. ${ }^{7}$ Despite its usefulness, however, this type of exercise is rather

\footnotetext{
${ }^{3}$ See Ferreyra (2007), who applied her parameter estimates to the simulation of private school vouchers.

${ }^{4}$ See, for instance, Aaronson (1999), Card and Payne (2002), Dee (2000), Downes (1992), Hoxby (2001), Murray et al (1998). For the case of Michigan, see Cullen and Loeb (2004), Guilfoyle (1998), Papke (2005), and Roy $(2003,2004)$.

${ }^{5}$ See Keely (2005) for Kentucky, Epple and Ferreyra (2007) and Roy (2004) for Michigan.

${ }^{6}$ The sheer dollar amount involved in litigation over adequacy of school funding points to the need for analytical rigor. For instance, one of the most recent court rulings in school finance came in November 2006, in Campaign for Fiscal Equity v. State of New York. Ending a thirteen-year lawsuit, New York's court of appeals ruled that the state must spend an additional \$1.93 billion for New York City public schools, short of the almost $\$ 5$ billion requested by the plaintiffs. For information about current and past school finance litigation, see http://schoolfunding.info.

${ }^{7}$ Keane and Moffitt (1998), Lumsdaine et al (1994), and McFadden et al (1997) use regime shifts over time to validate their models by estimating the model with data from one regime and predicting the effects of the other. Todd and Wolpin (2006) use data from a randomized social experiment to estimate the model using data from the control group and validate it on data from the treatment group. Lise et al (2003) use a model calibrated to replicate a small social experiment in order to predict the equilibrium effects of a large-scale program. Keane and Wolpin (2006) exploit the non-random state level variation in welfare policies to estimate a model of welfare participation using data for a set of states, and validate the model on states with different policies.
} 
uncommon, perhaps because the opportunities for external validation based on regime shifts are quite rare (Keane and Wolpin (2006)). In this paper, then, Proposal A is not only the object of policy analysis but also the source of regime shift for model validation. Furthermore, this is the first attempt to validate a general equilibrium model of multiple jurisdictions, of the type commonly used to analyze large-scale policies in education, housing and environmental quality, among others.

I estimate the model through full-solution methods. The fact that these complex models often lack closed-form solutions complicates the search for estimation methods that ensure that all the equilibrium conditions hold. Whereas other researchers have relied on two-step procedures that exploit equilibrium necessary conditions, ${ }^{8}$ I apply the onestep, full solution estimator developed in Ferreyra (2007), which is uniquely suited to estimate an equilibrium model because computing an equilibrium is searching for an allocation that fulfills all the equilibrium conditions. My computational representation of Detroit includes the actual number of districts (83) and is thus richer than that of previous studies. In addition, I use the actual state aid formulas to capture the determination of school revenues rather than the simplifications used in previous estimation. ${ }^{9}$ Yet this richness, coupled with the need to compute the equilibrium thousands of times during estimation, means that the estimation is only feasible because of my fast equilibrium computation, which is based on Ferreyra (2007).

Estimating the model permits the recovery of parameters that are of interest in their own right, such as the importance of peer quality, proxied by parental income, in the production of school quality. In contrast with recent studies estimating Tiebout models

\footnotetext{
${ }^{8}$ See, for instance, Epple and Sieg (1999) and Bayer et al (2005).

${ }^{9}$ Calabrese et al (2006) and Ferreyra (2007) use simplifications of actual rules, whereas Bayer et al (2005) do not model the determination of revenues.
} 
with peer effects, ${ }^{10} \mathrm{I}$ am the first to use school achievement data (pass rates on math exams) to identify the importance of peer quality. Although the lack of individual-level data prevents the identification of the mechanisms that give rise to actual peer effects, the corresponding estimates indicate that my measure of peer quality is more important than spending in the production of school quality, a finding with relevant implications for policy analysis.

My framework for large-scale policy analysis is similar to Sieg et al (2004) in the use and estimation of a Tiebout model. Nonetheless, while they conduct policy analysis for fixed levels of the local public good, I allow school quality to adjust endogenously as revenues and student bodies change through household relocation and voting. Thus, my approach is particularly adept to study the equilibrium effects of large-scale policies.

To assess the effects of Proposal A, one cannot directly compare 1990 and 2000 data because the metropolitan area experienced other changes in the decade besides the school funding reform. Hence, I use my parameter estimates to compare two equilibria which only differ in the school funding regime. My analysis of Proposal A indicates that since both the tax and revenue reform in Proposal A favor urban and low-income districts, some middle and high-income households migrate there, although these relocations are limited. Property values, in turn, rise in the favored districts but fall in high-income jurisdictions. Whereas the revenue reform eliminates some variation in school revenue, it less effectively shrinks the school quality gap because it affects the lesser important input for school quality and only induces small demographic changes, which means that peer qualities do not change much. Low-income households are Proposal A's clear winners

\footnotetext{
${ }^{10}$ See Calabrese et al (2006) and Ferreyra (2007).
} 
because they are favored by higher revenue and school quality, lower property taxes, and greater income redistribution.

Moreover, I investigate alternative school finance regimes -a retooling of the district power equalization prevailing before Proposal A, and a uniform foundation. My analysis suggests that these policies also favor poor districts, and a uniform and high foundation yields the highest school quality gains of the policies considered here. However, not even this fiscally costly policy closes much of the achievement gap across

districts, because the importance of peer quality limits the ability of revenue-based policies to raise performance in low-achievement districts. This, in turn, points to the relevance of policies which favor these districts yet do not rely -at least not solely- on revenues.

The remainder of this paper is organized as follows. Section 2 highlights some changes in the Detroit metropolitan area between 1990 and 2000. Section 3 presents the theoretical model, and section 4 describes the model's computational version. Section 5 presents the estimation strategy; section 6 discusses the estimation results and section 7 presents the results from the out-of-sample prediction exercise. Section 8 presents the policy analysis, and section 9 concludes.

\section{Detroit in 1990 and 2000}

A central piece of my framework is the computation of the equilibrium as a function of the model's exogenous variables. The endogenous variables of interest are district average household income, rental value, spending per student, and school quality. The exogenous variables are the state school finance regime, the metropolitan area income distribution, the district-level stock of non-residential property, and the neighborhood-level quantity 
and quality of housing. Hence, in this section I characterize Detroit in 1990 in terms of the endogenous variables, and describe the changes in the exogenous variables over the decade. These changes, in turn, are responsible for predicting different equilibria in 1990 and 2000. I focus on the comparison between 1990 and 2000 because demographic and property value data, which come from the Census, are only available every ten years. Whereas it is interesting to understand and model the determination of the value of the exogenous variables, particularly those related with the housing stock, such a task lies beyond the scope of this paper.

Detroit is the largest metropolitan area in the state of Michigan. It comprises eighty-three school districts, and in 1990 it had a population of about 3.93 million. About a quarter of the population lived in the city of Detroit, which is coterminous with the largest district in the metropolitan area (Detroit Public Schools). In contrast, the second largest district (Utica Community School District) comprised only 3 percent of the population, and among the eighty-two districts outside the city of Detroit the average share of population was about 0.9 percent.

Income and rental value data pertain to households with children in K-12 schools and come from the 1990 and 2000 School District Data Books. Revenues come from the 1989 and 1999 Bulletin 1014 from Michigan’s Department of Treasury, and pass rates for the fourth grade math test are from Michigan’s Department of Education. ${ }^{11}$ Dollar figures are expressed in 2000 dollars. As Figures 1a and 1b show, in 1990 there was considerable

\footnotetext{
${ }^{11}$ Rental values are calculated by annualizing average owner-occupied house values with the user cost rate. For simplicity, rents are omitted in this calculation because Proposal A's property tax reform applied only to owner-occupied housing units. The series of comparable achievement data begins in 1991, and the pass rate is computed as the percent of students who obtain a grade of "satisfactory" in the state's math test. Throughout, demographic data refer to Census years, and school-related data refer to the Fall of the corresponding school year. Revenue, spending and aid are per-student measures, and the terms "revenue" and "spending” are interchangeably used.
} 
variation in income and housing value across districts, with Detroit Public Schools ranking almost at the bottom. Similarly, local and state revenues differed widely across districts (Figure 1c) as did school achievement, measured by the pass rate in fourth grade math exams (Figure 1d). District average income, rental value, per-pupil revenue, and pass rates were highly and positively correlated.

As mentioned before, Proposal A was an important development for the metropolitan area over the decade. Figure 2 displays revenues the year before the reform ("base revenue”) and the foundation allowances guaranteed by the state in 1999. As the figure shows, the reform maintained the weak ordering of districts by revenue. Furthermore, the dollar changes in revenue were relatively small in the metropolitan area, although low- and high-revenue districts were clearly the gainers and losers in this reform, respectively. ${ }^{12}$ Nonetheless, when measured against revenues in 1989 instead of 1993, the percent gains in revenue over the decade were quite pronounced for several districts (Figure 4a). In addition, in 1991 Michigan implemented the Michigan Educational Assessment Program (MEAP), whose average pass rates rose from 34 percent in 1991 to 70 percent in 2000. Michigan also expanded public school choice and established public school accountability during the period of interest, ${ }^{13}$ although these seem to have gained strength only after 2000 (Cullen and Loeb (2004), Courant et al (2003)), suggesting that at least a fraction of the large improvement in MEAP scores might have been due to the progressive learning about the test on the part of teachers and students.

\footnotetext{
${ }^{12}$ Revenue gains were particularly pronounced for Michigan rural districts, located outside the Detroit metropolitan area.

${ }^{13}$ See Cullen and Loeb (2004) and Courant, Cullen and Loeb (2003). In spite of the expansion of public school choice (open enrollment across districts within the same county, and charter schools), only a small fraction of students were enrolled in choice programs by 2000.
} 
Moreover, the metropolitan area income distribution also changed over the decade. While all segments of the income distribution experienced real gains, these were greater for the high and particularly low ends. For instance, at the deciles of the household income distribution on which I focus for computational purposes $-10^{\text {th }}, 30^{\text {th }}, 50^{\text {th }}, 70^{\text {th }}$ and $90^{\text {th }}$ percentiles- real income grew by an approximate 24, 9, 8, 12 and 12 percent respectively.

Figure 3 depicts average housing quality. ${ }^{14}$ As the figure shows, there was considerable variation in housing quality in 1990, and some neighborhoods in the central city had almost the lowest quality. Whereas the housing stock in the metropolitan area grew by 6.7 percent, most of the growth took place in the outer suburbs. Of interest in this paper is the change in each neighborhood's share of housing stock relative to the metropolitan area's (Figure 4b). The central city, in particular, went from 27 to 23 percent of the total stock. Moreover, housing qualities also changed (Figure 4c). Relative to their 1990 quality, the outer suburbs experienced the greatest improvement, although some neighborhoods in the central city improved as well.

\section{The Model}

The model is based on Ferreyra (2007) and Nechyba (1999). In the model, a metropolitan area is populated by a continuum of households, each one endowed with a house. The set of houses in the metropolitan area is partitioned into school districts, and the size of the housing stock equals the measure of endowed houses. Every district $d$ is in turn partitioned into neighborhoods; there are $H$ neighborhoods in total in the metropolitan area. Although houses may differ in quality across neighborhoods, they have the same quality and rental price within a given neighborhood. The housing stock cannot be varied

\footnotetext{
${ }^{14}$ The calculation of housing quality parameters is explained in Section 4.
} 
in quantity or quality. Each household has one child, who must attend a school. Schools are public, and there is one public school in each district. Since a child may only attend the public school where the household resides, choosing locations is equivalent to choosing schools.

Households are heterogeneous in endowment (house plus income, with $I$ income levels in the metropolitan area) and in idiosyncratic preferences for locations. The following Cobb-Douglas utility function describes household preferences:

$$
U(\kappa, s, c, \varepsilon)=s^{\alpha} c^{\beta} \kappa^{1-\beta-\alpha} e^{\varepsilon}, \quad \kappa=k_{d h}
$$

where $\alpha, \beta \in(0,1), k_{d h}$ is an exogenous parameter representing the inherent quality of neighborhood $h$ in district $d$ (i.e., housing size and age, geographic amenities, etc.), $c$ is household consumption, $s$ is the quality of the child's school, and $\varepsilon$ is the household's idiosyncratic preference for the location. For a given household, $\varepsilon$ varies across locations. Furthermore, $\varepsilon$ is distributed according to a continuous distribution $G(\varepsilon)$, and is independently and identically distributed across locations for a given household and across households.

Household $i$ seeks to maximize utility (1) subject to the following budget constraint:

$$
c+\left(1+t_{d}\right) p_{d h}+T=\left(1-t_{y}\right) y_{n}+p_{n}
$$

where $y_{n}$ is the household's income, $t_{y}$ is the state income tax rate, $p_{n}$ is the rental price of the household's endowment house, and the right-hand side is the household's total income. Thus, the household chooses to live in location $(d, h)$ with housing price $p_{d h}$ and property tax rate $t_{d}$, and uses the remaining income for consumption $c$.

All schools produce school quality $s$ according to the following production 
function:

$$
s=q^{\rho} x^{1-\rho}
$$

where $\rho \in[0,1], q$ stands for the school's average peer quality and $x$ is spending per student at the school. In district $d$, the school's average peer quality is $q_{d}=\bar{y}_{d}$, where $\bar{y}_{d}$ is the average household income in the district. Thus, peer quality captures parental inputs outside spending that are positively associated with household income, such as parental engagement in the student's and the school's activities (McMillan (2000)). District d's spending per student is $x_{d}$, funded by a combination of local property and state income taxes as shown below:

$$
x_{d}=t_{d}\left(P_{d}+Q_{d}\right) / n_{d}+A I D_{d}
$$

where $n_{d}$ is the measure of households in district $d, A I D_{d}$ is the state aid per student for district $d$, and $P_{d}$ and $Q_{d}$ are the values of residential and non-residential district property in the district, respectively. ${ }^{15}$ While the public school finance described in this section applies to the pre-reform environment, in section 4 I note the modifications that apply to the post-reform environment.

Households choose locations $(d, h)$ and hence schools to maximize their utility subject to their budget constraint, while taking tax rates $t_{d}$, district public school qualities $s_{d}$, prices $p_{d h}$, and community compositions as given. Migrating among locations is costless, and the household may choose to live in a house other than its endowed house. In addition, households vote on local property tax rates, taking their location, property values, the state aid formula explained below, and the choices of others as given.

\footnotetext{
${ }^{15}$ For simplicity, I model non-residential property as owned by an absentee landlord who does not participate in the elections to set property tax rates, and I assume that its supply is inelastic. Hence, property taxes on non-residential property are fully capitalized, and the gross-of-tax rental price of non-residential property remains constant.
} 
Households’ preferences over property tax rates are single peaked, and property tax rates in each district are determined by majority voting.

The state cooperates in financing education in district $d$ by providing the perstudent aid $A I D_{d}$, funded by a state income tax whose rate $t_{y}$ is set to balance the state's budget constraint. Before Proposal A, the state applies a District Power Equalization (DPE) regime which guarantees a dollar yield per mill ${ }^{16}$ levied, and exogenously sets the guaranteed tax base per student (GTB) $G$ such that per-student aid for district $d$ is given by this formula:

$$
A I D_{d}=\max \left(0, t_{d}\left(G-\left(P_{d}+Q_{d}\right) / n_{d}\right)\right)
$$

which voters internalize when voting for local property taxes. ${ }^{17}$

An equilibrium in this model specifies a partition of the population into districts and neighborhoods, local property tax rates $t_{d}$, a state income tax $t_{y}$, house prices $p_{d h}$, such that: (a) every house is occupied; (b) property tax rates $t_{d}$ are consistent with majority voting by residents who take their location, property values, and the choices of others as given when voting on local tax rates; (c) the budget balances for each district; (d) the state budget balances, and (e) at prices $p_{d h}$, households cannot gain utility by moving. Whereas the equilibrium is proved to exist with a finite number of household types (Nechyba (1999)), for the case of an infinite number of household types I compute the equilibrium based on conditions which are sufficient to determine whether an allocation is an

\footnotetext{
${ }^{16}$ Property tax rates are often expressed in mills. A mill is the amount of dollars to be paid for each $\$ 1,000$ worth of assessed value. Hence, a one-mill rate is equivalent to a rate of $0.1 \%$.

${ }^{17}$ The actual formula adds a flat grant, $f$, to the second branch of the max operator. I omit the flat grant here because it is very small in dollars. In addition, voters' internalization of the formula that includes the flat grant has the potential to generate non-single peakedness of preferences over tax rates because for a district with $G<(P+Q) / n$ and a given value of the flat grant $f$, it is possible to have a positive, negative, or zero value for $f+t(G-(P+Q) / n))$ depending entirely on the property tax rate $t$. Thus, the median voter may maximize his utility at multiple property tax rates.
} 
equilibrium. $^{18}$

\section{The Computational Version of the Model}

The estimation strategy involves computing the equilibrium for each metropolitan area at alternative parameter points to search for the point that minimizes the distance between the predicted equilibrium and the observed 1990 data. The out-of-sample exercise, in turn, involves computing the 2000 equilibrium using the parameter estimates, and comparing it to the observed 2000 data. Since the equilibrium does not have an analytical solution, I solve for it through an iterative algorithm for a tractable representation of the Detroit metropolitan area. Thus, this section describes the representation of districts, neighborhoods, household types and school funding regimes, and the main characteristics of the algorithm employed.

\section{Community Structure and Households}

My computational representation of the Detroit metropolitan area includes the actual number of districts. I construct neighborhoods such that the central city has the ten neighborhoods identified by the city's actual classification of Census tracts into neighborhoods, and the remaining districts -all of which are very small- have one neighborhood each. A neighborhood's size is proportional to its actual number of housing units in 1990 or 2000 as needed.

\footnotetext{
${ }^{18}$ With a finite number of household types, the allocation of households to locations is unique if there is sufficient variation in district average housing quality (Nechyba (1999)). Ferreyra (2007) discusses uniqueness of equilibrium in a model with an infinite number of household types. Simulations for a variant of the current model have shown that the equilibrium is robust to the selection of different initial prices and assignments of households to locations, and that the equilibrium at the parameter estimates is locally unique.
} 
In the theoretical model each neighborhood is composed of a set of homogeneous houses, so that neighborhood $h$ in district $d$ has a neighborhood quality index equal to $k_{d h}$. I construct this index for 1990 using 1990 Census tract data for the metropolitan area as follows. ${ }^{19}$ I regress the logarithm of tract average rental price on housing and neighborhood characteristics and school district fixed effects. Then I compute each tract's neighborhood quality as the tract's fitted rental value net of the school district fixed effect. Thus, the quality measure captures housing and neighborhood characteristics excluding school quality. Finally, I set the neighborhood's quality index equal to the neighborhood's median tract's quality.

To facilitate the comparison of the 1990 and 2000 neighborhood qualities, I apply the 1990 regression coefficients to the 2000 data to calculate the 2000 fitted rental values and neighborhood quality indexes. This ensures that the 1990 and 2000 indexes for a given tract differ solely because of the observed differences housing and neighborhood characteristics. Since 36 percent of the tracts in the metropolitan area changed boundaries between 1990 and 2000, I use tract-level data from the 1990 Long Form in 2000 Boundaries and the 2000 Long Form, which are normalized to the 2000 boundaries.

As for households, I consider income levels equal to the $10^{\text {th }}, 30^{\text {th }}, 50^{\text {th }}, 70^{\text {th }}$ and $90^{\text {th }}$ percentiles of the income distribution of households with children in grades $\mathrm{K}$ through 12 in the metropolitan area in 1990 or 2000 as needed. Income and housing endowments are independently distributed, and the equilibrium computation begins with the same distribution of income across neighborhoods, equal to the observed metropolitan area's. Since households in the model differ not only in endowment but also in idiosyncratic preferences for locations, I assume that $\varepsilon$ follows a type I extreme value distribution with

\footnotetext{
${ }^{19}$ This procedure follows Ferreyra (2007).
} 
scale parameter $1 / b$, where $b>0$. Thus, $F(\varepsilon)=\exp (-\exp (-\varepsilon / b))$, and the variance of $\varepsilon$ equals $(1 / 6) \pi^{2} b^{2}$.

\section{School Finance}

Under the DPE regime prevailing in Michigan until 1993, district d's state aid, $A I D_{d}$, was determined by the state aid formula in (5), and local property tax revenue by the first term of (4). Although one would expect these expressions to hold when applied to actual data on $P, Q, n, t$ and $G$, the fact that they do not means that a model using them would hardly fit the data. Hence, I search for the implicit formula for which (4) and (5) hold. Furthermore, since DPE treats residential and non-residential property equally but Proposal A does not, I need to quantify each type of property separately to compare policy outcomes. The Appendix describes the implicit formula and the property tax base quantification. Furthermore, under DPE the state funded state aid mostly through income and sales taxes. Since consumption, taxed by the sales tax, is proportional to income, I simplify by considering only income taxes. Hence, in my computations the state budget

constraint is $t_{y} Y=\sum_{d} A I D_{d} n_{d}$, where $Y$ is total income in the metropolitan area.

In contrast with DPE, Proposal A established a foundation grant system by which the state guarantees each district a per-student revenue for operating expenses equal to its foundation allowance. A district's foundation allowance is based upon its local and state revenue before Proposal A ("base revenue”). As a function of 1993 base revenues expressed in 1999 dollars ( $x$ in the formula below), the foundation allowances ( $f a$ ) for 1999 were determined as follows: 


$$
f a= \begin{cases}5,700 & \text { if } x \leq 5,502 \\ .833 x+1114.34 & \text { if } x \in(5,502,7,494) \\ .867 x+860 & \text { if } x \geq 7,494\end{cases}
$$

Under Proposal A the state requires each district to levy 18 mills on nonresidential property and covers the difference between the foundation allowance and this local revenue through the following state taxes: a 6-mill tax on residential and nonresidential property, and sales and income taxes. From (6) it is clear that high-revenue districts were assigned correspondingly high foundation allowances, yet for fiscal reasons the state only guarantees foundation allowances up to a threshold, the "maximum state guarantee,” equal to $\$ 7,200$ in 1999 . Districts with foundation allowances above this threshold, or "hold harmless districts," may levy up to 18 additional mills on residential property in order to cover the difference between their foundation allowance and the maximum state guarantee.

To compute the Proposal A equilibrium, I first compute the DPE equilibrium that would have prevailed in 2000, and then determine the foundation allowance for each district as a function of the predicted 2000 DPE spending by applying (6). Hence, a district with a DPE spending below the maximum state guarantee has a proposal A spending equal to its foundation allowance $f a_{d}$, and its state aid is given by $A I D_{d}=f a_{d}-\bar{t}_{Q} Q_{d} / n_{d}$, where $\bar{t}_{Q}$ is the required 18 mills on non-residential property tax rate. Households in this district do not vote for property taxes. A hold-harmless district, in contrast, has spending $x_{d}=\min \left(f a_{d}, \bar{f}+t_{d} P_{d} / n_{d}\right)$ where $\bar{f}$ is the maximum state guarantee, and $t_{d}$ is the property tax rate, chosen by majority voting, in excess of the 6 
mills levied by the state. ${ }^{20}$ This district receives state aid equal to $A I D_{d}=\bar{f}-\bar{t}_{Q} Q_{d} / n_{d}$.

Under proposal A, the state's budget constraint is $t_{y} Y+\bar{t} \sum_{d}\left(P_{d}+Q_{d}\right)=\sum_{d} A I D_{d} n_{d}$, where $Y$ is the total income in the metropolitan area, $\bar{t}$ is the 6 mills on all property levied by the state for the State School Aid Fund, $A I D_{d}$ is the state aid determined as explained above, and $t_{y}$ is the income tax rate, whose value is endogenously set to balance the state's budget. Both in the DPE and Proposal A equilibrium computations, voters are subject to the constraint that property tax rates must not surpass the maximum of 50 mills allowed by the Michigan constitution. ${ }^{21}$

\section{The Algorithm}

In the model, the parameter vector is $\theta=(\alpha, \beta, \rho, b)$. To compute the equilibrium for a given parameter point, the algorithm iterates as households choose locations and schools and vote for property taxes until no household gains utility by choosing differently. The input for the algorithm consists of data for the model's exogenous variables -community structure, quantity and quality of housing stock in each neighborhood, non-residential property, metropolitan area income distribution, and state aid rule- and the initial distribution of household types and housing prices. The output is the computed equilibrium, which yields the predicted values of the variables of interest in the estimation and out-of-sample prediction. ${ }^{22}$

\footnotetext{
${ }^{20}$ This is a simplification of the actual rule because it does not consider that beyond the first 18 additional mills on residential property it is possible to raise further mills on all property (Adonizio et al (1995)). Without this simplification single-peakedness may be lost. As it turns out, in reality very few districts raise mills beyond the first 18 additional mills on residential property.

${ }^{21}$ This millage, which applies to assessed property values, is approximately equal to 200 mills, or 20 percent, when applied to property market values annualized to yield rental values.

${ }^{22}$ More details on the algorithm can be found in Ferreyra (2007).
} 


\section{Estimation}

In the estimation I match the observed and simulated values of the following district-level variables: $y_{1}=$ average household income, $y_{2}=$ average housing rental value, $y_{3}=$ average spending per student in public schools, and $y_{4}=$ district fraction of students who pass the fourth grade math test normalized by the metropolitan area’s highest fraction (often called "school quality" in what follows). ${ }^{23}$ These variables illustrate the distribution of households and housing values across districts, and the resulting revenue and achievement in the districts' public schools.

Let $D$ denote the total number of districts in the sample $(D=83)$, and use $i$ for an individual district, with $n_{i}$ being the number of housing units sampled in district $i$. Denote by $X_{i}$ the set of exogenous variables for district $i$, such that $X_{i}=x_{i} \cup x_{m} \cup x_{-i}$, where $x_{i}$ is district i's own exogenous data (number of neighborhoods, stock of non-residential property, and neighborhood size and housing quality), $x_{m}$ is exogenous data pertaining to metropolitan area $m\left(10^{\text {th }}, 30^{\text {th }}, 50^{\text {th }}, 70^{\text {th }}\right.$ and $90^{\text {th }}$ income percentiles, and school funding regime), and $x_{-i}$ is the "own" data from the other districts in the metropolitan area. I assume the following:

$$
E\left(y_{j i} \mid X_{i}\right)=h_{j}\left(X_{i}, \theta\right) \quad j=1, \ldots 4 ; \quad \mathrm{i}=1, \ldots \mathrm{D}
$$

where the $h$ 's are implicit nonlinear functions that express the equilibrium value of each endogenous variable I match as a function of the exogenous data and the parameter vector $\theta$. Since the $y_{j i}$ 's are sample means, $C\left(y_{j i}, y_{k i^{\prime}} \mid X_{i}, X_{i^{\prime}}\right)=\sigma_{j k} / n_{i}=\sigma_{j k i}$ if $i=i^{\prime}$ and 0

\footnotetext{
${ }^{23}$ The school quality predictions are also normalized by the highest predicted quality in the metropolitan area in order to fit pass rates, which lie between zero and one whether or not they are normalized. The normalization means that the focus is on the achievement gap relative to the highest-achievement district. Hence, an increase in the normalized measure for a given district represents a closing of this gap.
} 
otherwise, and $V\left(y_{j i} \mid X_{i}\right)=\sigma_{j j} / n_{i}=\sigma_{j}^{2} / n_{i}=\sigma_{j i}^{2}=\sigma_{j j i}$, where $\sigma_{j k}$ and $\sigma_{j}^{2}$ denote population covariances and variances, respectively.

I estimate the model using Feasible Generalized Non-Linear Least Squares (FGNLS) and account for heteroskedasticity across observations and cross-equation covariances. In the first stage of FGNLS I find the value of $\theta$ that minimizes the following loss function:

$$
L(\theta)=\sum_{j=1}^{4} \sum_{i=1}^{D}\left(y_{i j}-\hat{y}_{i j}(\theta)\right)^{2}
$$

I use the residuals from this stage to compute the $\hat{\sigma}_{j k i}$ 's needed to transform the variables in order to account for heteroskedasticity and cross-equation covariances. In the second stage I minimize the following loss function in the transformed variables:

$$
\tilde{L}(\theta)=\sum_{j=1}^{4} \sum_{k=1}^{4} \sum_{i=1}^{D}\left(y_{j i}^{*}-\hat{y}_{j i}^{*}(\theta)\right)\left(y_{k i}^{*}-\hat{y}_{k i}^{*}(\theta)\right)
$$

where $*$ denotes division by $\sqrt{\hat{\sigma}_{j k i}}$. The value of $\theta$ that minimizes this function, $\hat{\theta}$, is the estimate for the parameter vector.

The model is identified if no two distinct parameter points generate the same equilibrium. Formally, a sufficient condition for local identification is that the matrix of first derivatives of the predicted variables with respect to the parameter vector has full column rank when evaluated at the true parameter point. This condition requires sufficient variation in the exogenous variables across districts and is met when the matrix is evaluated at my parameter estimates. Intuitively, the parameters are identified as follows. Spending and housing prices identify the school quality coefficient on the utility function ( $\alpha$ ), as a higher $\alpha$ raises spending and most housing prices given that a house in a given 
location provides access to the location's school. Housing prices also identify the coefficient of consumption in the utility function $(\beta)$, because a higher $\beta$ raises household consumption and lowers housing prices. The level of spending, and the correlation between income and achievement, identify the elasticity of school quality with respect to peer quality $(\rho)$, as a higher $\rho$ raises this correlation and lowers spending. Furthermore, the Cobb-Douglas utility function means that the budget shares for spending and housing are equal to $\alpha^{*}=\alpha(1-\rho) /(1-\alpha \rho)$ and $h^{*}=(1-\alpha-\beta) /(1-\alpha \rho)$, respectively. Since $\alpha$ and $\rho$ cannot be identified from these shares only, achievement data is crucial to identifying $\rho$ and hence $\alpha$. Finally, the interjurisdictional variation in income, housing prices, spending and achievement identifies $b$, which is directly related to the variance of idiosyncratic preferences, since a greater $b$ makes household sorting depend less on income and more on idiosyncratic preferences, and thus leads to less residential segregation across districts.

While the empirical approach employed in this paper is most closely related to Ferreyra (2007), it differs as follows. For computational tractability, Ferreyra aggregates suburban districts into “pseudo-districts”. In contrast, this paper's representation of the Detroit metropolitan is much richer and uses the actual number of districts and city neighborhoods. Whereas identification in Ferreyra (2007) comes from variation across pseudo-districts and metropolitan areas, identification here relies on variation across districts within the Detroit metropolitan area. The peer quality parameter, identified through private school enrollment by Ferreyra, is identified here more directly through the variation in achievement and income across districts. Finally, given its focus on school funding reform this paper uses the actual state aid formulas rather than the simplifications used by Ferreyra, which permits a better fit of revenue data and enhances the usefulness of 
the model for policy purposes.

\section{Estimation Results}

Table 1 presents the parameter estimates for the model. These are highly significant, mostly as a result of fitting sample means based on large numbers of observations. The parameter estimates imply budget shares of 0.14 and 0.02 for housing and school spending, respectively, whereas the corresponding shares in the data are 0.16 and 0.08 respectively. While the implied housing share measures well against the data, the implied spending share falls short because the computational model incorporates the implicit subsidy to households with children from childless households and non-residential property owners. The estimated elasticity of school quality with respect to peer quality, $\rho$, implies that peer quality contributes more than spending to the production of school quality. Finally, the fact that the estimate for $b$ is close to zero implies a high degree of residential segregation across districts in the predicted equilibrium.

Figures 5a through 5d depict the predicted and observed values for district average income, rental value, spending, and school quality. The relatively high correlation between predicted and observed values for each variable $(.84, .88, .76$ and .83 respectively) indicates a reasonably good fit of the data, which is encouraging given the parsimonious parameterization of the model. The good fit of district average household income and rental value (Figures 5a and 5b, respectively) captures the observed residential sorting. Very high income or house values are under predicted because of the truncation of the empirical income distribution at the $90^{\text {th }}$ percentile. As Figure $5 c$ shows, the efforts to quantify property tax bases and to construct implicit funding formulas have helped fit 
spending. Furthermore, the model fits school quality quite well (Figure 5d), with the same caveats noted for income given the high estimate for $\rho$.

Table 2 shows the correlations between the matched variables for the observed and fitted values. The correlations for fitted values resemble the actual correlations reasonably well. The predicted school quality is more highly correlated with income and house value

- hence less with spending - than the observed school quality, while the predicted spending is less highly correlated with income and house value than the observed spending. However, fitting spending is probably the most challenging aspect of the estimation. Furthermore, the observed measure of school quality provides an imperfect measure of the corresponding theoretical construct and is likely affected by substantial measurement error (Kane and Staiger (2002)). In light of these limitations, I view the evidence presented here as indicative that the model successfully captures the patterns in the data.

\section{Out-of-Sample Prediction}

Since the 2000 foundation allowances are determined by the 1993/94 revenues, ideally one would have the exogenous data needed to compute the 1993/94 DPE equilibrium. Given that such data are not available, I feed the algorithm with the 2000 value of the exogenous variables and compute the equilibrium that would have prevailed in 2000 had the DPE regime been still operative. Based on this equilibrium I then compute Proposal A's equilibrium, using (6) to determine the corresponding foundation allowances given 
the 2000 DPE revenues. ${ }^{24}$ Thus, the success of the 2000 predictions partly depends on the success of the counterfactual 2000 DPE.

As mentioned in section 2, pass rates rose consistently over the decade, probably due to learning about the achievement test. When computing the 2000 equilibrium, I account for this phenomenon by raising school quality predictions by an additive constant such that when the constant is applied to the average 1990 predicted quality, the resulting proportional quality increase matches the proportional increase in observed average achievement over the decade. As for revenues, I measure 1999 actual revenues (and spending) through the foundation allowance. A district's predicted 1999 revenue equals the predicted foundation allowances if the district is not allowed to raise hold-harmless mills given its 2000 DPE revenues, and it equals the maximum guarantee plus the revenue from hold harmless mills otherwise.

Figures 6a through 6e depict the predicted and observed values for average income, rental value, foundation allowance, spending and public school quality. The model fits the data on income and house value well (Figures 6a and 6b), subject to the same caveats as the in-sample fit. The correlations between predicted and observed values are .82 and .86 for income and house value, respectively. As Figure 6c shows, there is a bunching of predicted allowances at the minimum foundation $(\$ 5,700)$ because the corresponding predicted DPE revenues are too low. Similarly, the over prediction of DPE revenues for other districts leads to over predicting their foundation allowances. However,

\footnotetext{
${ }^{24}$ In order to compute the 2000 DPE equilibrium, I need to choose a value for the GTB. Lacking information on what the GTB would have been in 2000, I choose the observed 1990 value expressed in 2000 dollars. To the extent that this GTB may be too low, the resulting DPE spending for low-revenue districts is also low, which means that in the simulations Proposal A provides them with revenue gains that are too high. This caveat should be taken into account when interpreting results for urban and low-income districts in section 8's counterfactuals. Hence, both the revenue gains and their induced effects under the different policies considered there are best viewed as an upper bound.
} 
the fact that the correlation between predicted and observed foundation allowances equals 0.71 reveals an overall good fit for this variable.

Figure 6d displays actual and fitted spending, which differs from the fitted foundation allowances because of the predicted hold-harmless mills for some districts. In the data, 22 districts are allowed to raise hold-harmless mills. Although there is no direct information on whether these districts raised additional mills in 2000, more recent evidence suggests that they might have done so. ${ }^{25}$ Of the actual 22 hold-harmless districts, the model correctly predicts the hold-harmless status of 14 districts, of which 8 are predicted to raise hold-harmless mills. Overall, revenue is well fitted, as the correlation between observed and fitted values equals .71. Finally, Figure 6e displays the observed and fitted school quality. The model correctly predicts an overall increase in school quality, and school quality is overall well fitted (the correlation between observed and predicted values is .69) although achievement is under predicted for a number of mediumperformance districts and slightly over predicted at the top.

A comparison between panel (a) of Tables 2 and 3 reveals that the correlations among the variables of interest did not change much between 1990 and 2000, except that school quality became less correlated with income, rental value and revenue. The reason is the ceiling effect in the improvement of achievement: since pass rates cannot surpass 100 percent, districts with 1990 high performance had little room for improvement, whereas the opposite was true for low-performance districts. As panel (b) of Table 3 shows, the 2000 observed correlations are reasonably replicated by the model although the predicted correlations of foundation allowance with income and rental value are relatively low

\footnotetext{
${ }^{25}$ For evidence that the vast majority of hold-harmless districts were raising hold harmless mills in 2005/6, see http://www.michigan.gov/mde/0,1607,7-140-6530_6605-47585--,00.html.
} 
because of the bunching mentioned above, and the predicted correlations of school quality with income and rental value are relatively high because the additive school quality constant does not fully capture the observed ceiling effect.

It is natural to ask whether the changes occurred between 1990 and 2000 are captured by the model. Hence, Table 4 displays the correlations between the observed and the predicted changes, the latter computed as the difference between the predicted values for 1990 and 2000. As the table shows, the model does reasonably well at predicting changes in the endogenous variables given the limitations noted above. Furthermore, the "observed data” row of Table 5 shows the pattern of changes that took place over the decade. Districts with lower revenue experienced greater absolute and relative increases in revenue, and greater reduction in property tax rates as well (the correlation between proportional change in revenue and absolute millage change is 0.27$)$. In addition, districts with lower income experienced greater income growth. One possible explanation for this phenomenon is that higher-income households might have migrated towards lowerincome locations in response to the higher revenues and lower property tax rates established by Proposal A. Another explanation is that because incomes grew proportionally the most for the low segment of the income distribution (see section 2), average income in the locations occupied by those households might have grown simply because the original inhabitants became richer. I re-examine this matter in section 8 .

Moreover, rental values grew the most in the districts with the lowest values, which benefited from the highest revenue increases, the largest property tax reductions, and the greatest increases in household income. Districts with the lowest initial school quality reaped the largest proportional gains, an outcome which is likely associated with the ceiling effect described above. Overall, it is encouraging that the observed pattern of 
changes is successfully captured by the model, as evidenced by the correlations in the “fitted data” row of Table 5.

To further explore changes, Table 6 displays the correlations among the proportional changes in the endogenous variables of interest and two exogenous variables. A comparison between panels (a) and (b) shows that the correlations among endogenous variables are reasonably replicated by the model, although with some overstatement. Relative to initial housing quality, proportional change in housing quality follows an inverted-U shape, as the distribution of house quality in 2000 has greater mass at the low and high ends than in 1990. As panel (b) shows, the model captures the fact that the locations with the greatest increase in housing quality experienced the greatest increase in household income, rental value and revenue, and correctly predicts the intensity of these relationships.

The correlations involving the change in district relative size are also captured by the model, although it should be noted that these correlations are almost totally driven by the city of Detroit, both in the data and the model. The reason is that change in relative size is almost negligible for districts outside the city of Detroit, and even for Detroit the change is not large. Hence, these correlations are basically a reflection of the changes experienced by the city of Detroit and are not necessarily related to the change in relative size per se. Although all neighborhoods in the city shrank, some of them gained in housing quality. The city's average income, property value, spending and school quality rose by 17, 106, 11 and 178 percent respectively. These changes are approximately matched by the model, which predicts increases of 24, 166, 4 and 254 percent respectively for income, property value, spending and school quality. 
To summarize, the model fits the out-of-sample data reasonably well. In particular, it is capable of capturing the direction and intensity of the changes in the endogenous variables associated with changes in housing, metropolitan area income distribution, and school finance. Furthermore, the fact that the predicted Proposal A equilibrium is broadly consistent with the data says that the predictions for the underlying 2000 DPE equilibrium are reasonable. This body of positive evidence, noteworthy given the inherent complexity of the model, provides a measure of confidence for the policy analysis in the next section.

\section{Policy Analysis}

In this section I investigate the effects of several school funding reforms including Proposal A. To predict the equilibrium for each funding policy I first compute the benchmark 2000 DPE equilibrium, and then the corresponding policy's equilibrium based on the benchmark. DPE is the natural baseline because it was the prevailing regime before the implementation of Proposal A. In order to focus exclusively on funding issues, school quality in these simulations does not include the additive constant used for the out-ofsample exercise, except when noted.

Table 7 characterizes the equilibrium for the baseline DPE and the alternative policies by focusing on school revenues, demographics, property values, school quality and fiscal considerations in panels (a), (b), (c), (d) and (e), respectively. Column 1 pertains to the DPE equilibrium, in which 14 out of 83 districts have property tax bases per student smaller than the GTB and hence receive state aid ( $\$ 460$ on average), funded by the income taxes paid mostly by households in high-income districts. ${ }^{26}$ Inter-district variation in

\footnotetext{
${ }^{26}$ In these simulations, "high-income districts" are those which are allowed to raise hold-harmless mills under Proposal A, and "low-income districts" are all others.
} 
revenue, income, property value and school quality across districts, measured by the ratio of the highest to the lowest value and the ratio of the $75^{\text {th }}$ to the $25^{\text {th }}$ percentile, paints a picture of considerable household segregation across districts and high variation of school revenues and quality. Urban and low-income districts display the lowest income, property values, revenues and achievement in the metropolitan area, and the highest property tax rates. The net income tax subsidy per student (per-student aid minus the household's income tax liability), which is a measure of redistribution, is positive for low-income jurisdictions yet negative for wealthier districts. Furthermore, since households in lowincome districts vote for low property tax rates, DPE has limited equalizing effectiveness precisely because it operates through the property tax. ${ }^{27}$

\section{Proposal A}

Column 2 of Table 7 displays the effects of Proposal A. As is clear from (6), the revenue reform means that the twenty-five districts with prior revenue above \$6,673 experience revenue losses, whereas the urban and low-income districts with revenues below \$5,502 experience revenue increases. The tax reform, in turn, favors all districts but particularly urban and low-income jurisdictions because they have the highest property tax rates in the baseline. In other words, both elements of Proposal A benefit urban and low-income districts proportionally the most.

As panel (a) shows, Proposal A accomplishes the goal of reducing the variation in revenue across districts, as it raises urban revenues by an average of 58 percent and lowers high-income districts’ revenues by an average of 18 percent. Furthermore, average income

\footnotetext{
${ }^{27}$ It can be shown that in the DPE regime characterized in section 4, the property tax rate that is voted upon does not depend on the magnitude of the GTB. Hence, equilibrium tax rates are mostly insensitive to the GTB magnitude.
} 
rises in urban districts (see panel (b)), because they attract higher income households through their revenue increase and property tax reduction. In contrast, by losing revenues and the ability to choose them, hold-harmless districts lose households to other districts, particularly to those with relatively good housing. As these relocations take place, income variation drops across districts. ${ }^{28}$ Nonetheless, the changes in average household income across districts are quite small, which indicates that the reform has little effect on household sorting, a result consistent with Epple and Ferreyra (2007) and Roy (2004). This is because housing quality in urban and low-income districts is so low that their benefits from Proposal A do not suffice to attract higher income households. In addition, Proposal A affects school spending, which is less important than peer quality in the production of school quality, and hence has limited ability to affect household behavior. Moreover, the small changes in household demographics induced by Proposal A suggest that the actual income gains experienced by the lowest income districts (see previous section) are more likely associated with the changes in the overall income distribution, which relatively favored the original residents of those districts, than with household relocation.

Changes in property values display a similar pattern as changes in income (see panel c). Because they reflect the net effect of lower property taxes and changed school revenues, urban districts attain the largest gains (3 percent on average) and high-revenue districts experience the largest losses (2 percent on average).

\footnotetext{
${ }^{28}$ In the case of income, the highest to lowest ratio is the same as for DPE and the other policies, whereas the $75^{\text {th }}$ to $25^{\text {th }}$ percentile ratio is lower for Proposal A and the other policies than for DPE. This indicates that while these policies induce relocation that favors low-income districts, the relocation is not enough to alter the income gap between the highest and lowest income districts.
} 
An important issue is whether Proposal A affects school quality (see panel (d)). Since peer quality has a prominent role in the production of school quality, and peer qualities do not change much across districts in the absence of large demographic effects, school qualities change at much lower rates than revenues. Urban districts, which experience the largest gains in revenue and peer quality, gain the most school quality (8 percent on average), while high-income districts lose the most (4 percent on average) by losing revenue and good peers. Hence, the variation in school quality shrinks, though not as much as the variation in revenue. The fact that equalization policies are more effective at reducing revenue variation than school quality variation is a theme in these simulations and shows the limitations faced by state aid policies, a point also made by Nechyba (2004). Furthermore, the contrast between Proposal A’s predicted average proportional change in school quality (0.05) and its observed counterpart over the decade (0.77) suggests that little of the observed increase in school quality is associated with Proposal A.

Whereas others have studied the relationship between revenue and achievement uncovered by Proposal A, it is interesting to examine whether my estimates are aligned with theirs. According to my simulations, an additional ten percent of revenue is associated with about two additional percentage points in the pass rate, similar to the estimates reported by Papke (2005) using data for the whole state of Michigan. In addition, in my simulations an extra $\$ 1,000$ is associated with about 1.5 additional percentage points in the pass rate, below the 4 or 5 additional points reported by Roy (2003) and the 6 points reported by Epple and Ferreyra (2007). However, when I compare my predicted 2000 and 1990 equilibria, an additional \$1,000 is associated with about 6 additional points. This is because the predicted 2000 equilibrium incorporates the 
observed general improvement in school quality, which proportionally favors urban and low-income districts - which are, in turn, those with the largest revenue gains and the greatest room for academic improvement. Thus, my results on the relationship between revenue and achievement in Detroit are broadly consistent with those in the literature.

Panel (e) reflects the fiscal impact of the reform. Relative to the baseline, the property tax reform leads to lower residential yet higher non-residential taxes. Furthermore, greater reliance on state funding leads to higher income taxes, and the share of revenues funded by income taxes rises from 9 to 53 percent. Non-residential property taxes also fund a higher share of revenue under Proposal A, thus providing a subsidy to the average household. Including residential and income taxes, the average household undergoes a slightly higher tax burden because the average revenue is higher.

In contrast with DPE, students in high-income districts receive some state aid under Proposal A. At the same time, these households pay greater income tax bills to finance the metropolitan total expense in foundation allowances. Hence, their net income tax liability goes from $\$ 500$ to $\$ 4,000$. The reverse is true for students in other districts, which on average go from an income tax subsidy of $\$ 100$ to one of $\$ 1,100$. Although high-income districts undergo, on average, almost the same tax burden in DPE and Proposal A, the difference is that under DPE most of this burden consists of property taxes which fund their own schools, yet of income taxes that fund others districts' schools under Proposal A.

While low-income districts benefit from the property tax reform, revenue changes, and income redistribution, high-income districts lose revenue and property values. Furthermore, high-income districts lose the direct connection between tax liabilities and school revenues. To investigate the importance of their constraint on property taxes, I 
simulate a variant of Proposal A that allows high-income districts to raise their desired level of property taxes. As it turns out, the constraint is not binding because high-income districts bear most of Proposal A's income tax burden. Hence, their disposable income is affected to the point that it is not optimal for them to raise additional mills even when allowed to do so.

Since Proposal A entails a tax reform and a revenue equalization, it is of interest to disentangle their effects. Hence, I simulate a tax reform such that each district's revenue remains the same as in DPE, the foundation allowance equals the DPE revenue, and schools are funded as in Proposal A except that hold-harmless districts raise all the residential mills needed to reach their foundation so that their revenue remains the same. Column 3 displays the effects of this tax reform. Its main impact is on property values, which fully capitalize the reduction in property taxes as gross-of-tax property values are the same, on average, under DPE and the tax reform. ${ }^{29}$ Hence, the reform leads to overall housing appreciation (4\% on average), particularly in urban districts which have the highest property tax rates under DPE. Of all the policies studied here, the tax reform is the only one to increase all property values; the other reforms generate gains and losses for low and high-income districts, respectively. Furthermore, this full capitalization rate is consistent with the empirical evidence from Epple and Ferreyra (2007) and aggregate-data results from Guilfoyle (1998).

\section{Alternative Policies}

\footnotetext{
${ }^{29}$ If the tax reform replaced residential property taxes only with income taxes, then the gross-of-tax property value of every house would be the same before and after the reform. However, the fact that some of the revenue from residential property taxes is replaced by non-residential property taxes creates a subsidy for households, which thus experience a positive yet small income effect. This leads to slight changes in the value of individual houses although the average gross of tax property value remains the same.
} 
One of the goals of Proposal A was to equalize revenues across districts. However, alternative policies could have been implemented to this end. For instance, the state could have adjusted the original DPE regime by raising the GTB in order to secure greater revenue equalization. Hence, Column 4 of Table 7 shows the effects of doubling the nominal GTB, which amounts to a real increase of about 66 percent relative to the baseline. In this adjusted DPE, the initial fourteen in-formula districts receive at least twice as much aid as in the baseline, and ten additional districts are covered by the formula. On average, revenues rise by about 10 percent, and most of the gains accrue to urban districts. Although this policy reduces revenue variation relative to the original DPE, it does so less successfully than Proposal A because it relies on property taxes. At the same time, the adjusted DPE hurts high-income districts less than Proposal A because it preserves their ability to raise property taxes. Since the adjusted DPE policy alters revenues less than Proposal A, it motivates even smaller demographic changes. Consequently, school qualities also change less.

Alternatively, the state could have fully equalized revenues through a foundation of uniform level across districts. Hence, Columns 5 and 6 display the effects of setting revenues equal to the DPE median and highest revenue in the "low foundation" and "high foundation" regimes, respectively. The tax structure is the same as that of the tax reform studied above.

Under the low foundation regime, urban and suburban districts experience average revenue gains of 69 and 24 percent respectively, yet high-income districts lose revenue at an average rate of 38 percent because they have DPE revenues above the median. Although this regime induces greater demographic changes than the policies examined so far, the changes are still small. Moreover, the policy boosts urban and some suburban 
property values at the expense of high-income districts. From a fiscal perspective, the tax reform that accompanies the equalization leads to a higher share of income tax revenue and lower share of residential property tax revenue than under DPE. Nonetheless, the redistribution through income tax is greater than under Proposal A because the districts that gain revenue do so at a higher rate.

In contrast to the average revenue gain of 35 percent, the average school quality gain for the low-foundation regime is only 11 percent. School quality variation indeed falls though not as much as the revenue variation, showing again the limits of revenue equalization policies. The question, then, is whether equalizing revenue at a higher level would accomplish greater school quality gains, a question addressed by the highfoundation simulation. Although this policy leads to an average revenue gain of 228 percent, the demographic effects are the same as those of the low-foundation program. This result, which may be surprising, is due to the fact that the two foundation programs eliminate spending as a source of variation across districts, hence leaving housing quality as the only exogenous amenity on which households sort. Since housing qualities are the same in both programs, so are households’ choices and school qualities. ${ }^{30}$

From a fiscal standpoint, the high foundation entails the greatest reliance on income taxes and the highest tax burden among the policies studied here. Furthermore, the high foundation leads to the lowest variation in property values because the decline in rental values for suburban and high-income districts is the highest (2 and 8 percent on average, respectively). This decline is even greater than under the low foundation regime

\footnotetext{
${ }^{30}$ Recall that my measure of a district's school quality is the district's achievement normalized by the metropolitan area's highest achievement. According to this measure, school quality is the same for each district in both foundation programs. Absolute (unnormed) achievement, on the other hand, is higher under the high equalization. Relative (normed) achievement highlights the fact that the gap between a given district and the highest achievement district is invariant to the foundation level used for the equalization.
} 
because disposable incomes are lower given the larger fiscal burden of the program. Hence, the high foundation only differs from the low foundation in that it leads to lower property values and higher fiscal burdens. It does not, however, further close the achievement gap across districts.

\section{Summary}

Several lessons emerge from the policy analysis conducted above. First, and not surprisingly, foundation regimes are most effective at equalizing revenues, followed by Proposal A which also features a foundation regime. Second, the policies considered here induce some, but not much, relocation to urban districts, whose housing quality is too low to attract middle and high-income households even when revenues for urban districts rise considerably. Third, these policies reduce variation in property values. Urban values rise in all cases, yet with the exception of the pure tax reform, property values in high-income districts drop. Fourth, a more aggressive equalization accomplishes greater school quality gains for urban and low-income districts directly through higher revenue, and indirectly through the peer quality improvement induced by demographic changes. However, in these simulations the direct channel is not strong because revenue has a weaker role than peer quality in school quality production. The indirect channel is not strong either because revenues, by not being prominent in the production of school quality, have limited power to induce relocation. Thus, revenue-based policies do not have much ability to close the achievement gap in the Detroit metropolitan area.

In light of this finding, the question is whether other types of policies might succeed. To investigate this matter, I simulate an augmented version of Proposal A that incorporates Proposal A’s tax and revenue reform, plus a school reform that benefits low- 
income, low-achievement districts proportionally the most. ${ }^{31}$ The effects of this policy on demographics, property values, and school revenues are very similar to those of Proposal A. However, the effects on school quality are remarkably different. The augmented Proposal A raises the average school quality from 0.50 to 0.69 whereas Proposal A only raises it to 0.52. On average, the augmented Proposal A attains proportional gains of 140, 49 and 16 percent for urban, suburban and high-income districts respectively. These gains are at least one order of magnitude higher than Proposal A's. When measured by the ratio of $75^{\text {th }}$ to $25^{\text {th }}$ school quality percentile, the achievement gap is equal to 1.51 under the augmented Proposal A, in contrast to 2.22 under Proposal A.

Thus, this simulation suggests that non-revenue based policies with greater proportional impact on low-performance districts are likely to be most effective in closing the achievement gap. Examples of these policies include accountability, curriculum targeting, and schools of choice, such as charter schools and private schools funded by vouchers, that serve low-achievement students differently from traditional public schools. Hence, the accountability policies enacted after 2000, and the strengthening of the charter school movement towards the end of the decade may well have been the most effective policies implemented by the state in terms of closing the achievement gap.

\section{Concluding Remarks}

In this paper I have presented an empirical framework for large-scale policy analysis. Because of their potential effects on several markets, large-scale policies must be

\footnotetext{
${ }^{31}$ I model this reform in the same way as the actual improvement in school quality observed during the decade - namely, as an increase of the same magnitude across districts which, once normalized by the highest achievement, becomes proportionally larger for low-achievement districts. To facilitate comparisons, I use the same school quality additive constant as for the out-of-sample exercise. In my simulation, this reform has zero marginal cost. While no reform has literally zero cost, the cost is this type of reform (see examples below) is plausibly quite small relative to that of certain revenue policies.
} 
evaluated in an equilibrium framework. While useful, the estimation of the relevant model does not guarantee the model's ability for out-of-sample prediction and counterfactuals which are, however, a key motivation for these models. Hence, I overcome this obstacle by using the very policy of interest as the regime shift that facilitates out-of-sample prediction. In particular, I apply my framework to study the effects of Michigan’s 1994 school finance reform (Proposal A) in the Detroit metropolitan area. I estimate the model with 1990 data, use the parameter estimates to predict the 2000 equilibrium, and compare the predictions with 2000 data. The reasonably good fit of the in- and out-of-sample data provides confidence in the model's suitability for policy analysis. According to my analysis, Proposal A had little impact on school quality. Furthermore, alternative revenuebased policies might not close much of the achievement gap either. While this paper is the first to use out-of-sample prediction in education, a similar approach could be applied to school finance reform in other states, other education reforms, or other large-scale policies in general.

A clear limitation of my study is the exogeneity of the housing stock. Although structural Tiebout models with endogenous housing have not been developed yet, this is an interesting direction for future research. ${ }^{32}$ Despite its limitations, the current model is broadly consistent with the in- and out-of sample data and therefore useful for short- and medium-run analysis. Successful out-of-sample exercises increase the confidence in our models and allow us to examine policies of costly implementation. Any rigor we can bring to this process is certainly desirable, and this paper is a step in that direction.

\footnotetext{
${ }^{32}$ See Frame (2007), who models the endogenous development of new housing prompted by changes in the income distribution and the obsolescence of the existing housing stock.
} 


\section{References}

Aaronson, Daniel. 1999. “The Effect of School Finance Reform on Population Heterogeneity.” National Tax Journal, 52(1): 5-29.

Adonizio, Michael, Philip Kearney and Henry Prince. 1995. “Michigan’s High Wire Act”. Journal of Education Finance, 20 (Winter): 235-269.

Bayer, Patrick, Robert McMillan and Kim Rueben. 2005. “An Equilibrium Model of Sorting in an Urban Housing Market”. Duke University Working Paper.

Calabrese, Stephen, Dennis Epple, Thomas Romer and Holger Sieg. 2006 "Local Public Good Provision: Voting, Peer Effects, and Mobility”. Journal of Public Economics, 90(6-7): 959-981.

Card, David, and Abigail Payne. 2002. "School Finance Reform, the Distribution of School Spending, and the Distribution of Student Test Scores”. Journal of Public Economics, 83(1): 49-82.

Courant, Paul, Julie Berry Cullen, and Susanna Loeb. 2003. “K-12 Education in Michigan.” In Michigan at the Millennium: A Benchmark and Analysis Of Its Fiscal and Economic Structure, ed. Charles Ballard, Paul N. Courant, Douglas C. Drake, Ronald Fischer, and Elisabeth R. Gerber, 1-23. Lansing, MI: Michigan State University Press.

Cullen, Julie Berry and Susanna Loeb. 2004. "School Finance Reform in Michigan: Evaluating Proposal A," in Helping Children Left Behind: State Aid and the Pursuit of Educational Equity, ed. John Yinger, 215:249. Cambridge, MA: MIT Press.

Dee, Thomas. 2000. "The Capitalization of Education Finance Reforms”. Journal of Law and Economics, 43 (April): 185-214.

Downes, Thomas. 1992."Evaluating the Impact of School Finance Reform on the Provision of Public Education: The California Case”. National Tax Journal, 45(4): 405-419.

Epple, Dennis and Maria Ferreyra. 2007. "School Finance Reform: Assessing General Equilibrium Effects”. Carnegie Mellon University Working Paper.

Epple, Dennis and Holger Sieg. 1999. "Estimating Equilibrium Models of Local Jurisdictions”. Journal of Political Economy, 107(4): 645-681.

Fernandez, Raquel and Richard Rogerson. 2003. "Equity and Resources: An Analysis of Education Finance Systems”. Journal of Political Economy, 111(4): 858-897.

Ferreyra, Maria. 2007. "Estimating the Effects of Private School Vouchers in Multi-District Economies". American Economic Review, 97 (3): 789-817.

Frame, David. 2007. “Urban Meiosis”. Carnegie Mellon University Working Paper.

Guilfoyle, Jeffrey. 1998. “The Incidence and Housing Market Effects of Michigan’s 1994 School Finance Reforms”. National Tax Journal Paper and Proceedings.

Hoxby, Caroline. 2001. "All School Finance Equalizations are Not Created Equal”. Quarterly Journal of Economics, 116(4): 1189-1231.

Kane, Thomas and Douglas Staiger. 2002. "The Promise and Pitfalls of Using Imprecise School Accountability Measures”. Journal of Economic Perspectives, 16(4): 91-114.

Keane, Michael and Robert Moffitt. 1998. “A Structural Model of Multiple Welfare Program Participation and Labor Supply”. International Economic Review, 39(3): 553-589.

Keane, Michael and Kenneth Wolpin. 2006."Exploring the Usefulness of a Non-Random Holdout Sample for Model Validation: Welfare Effects on Female Behavior”. Penn Institute for Economic Research Working 
Paper 06-006.

Keely, Louise. 2005. The Myth of School Finance Equalization, as told by Kentucky and North Carolina. University of Wisconsin-Madison Working Paper.

Lise, Jeremy, Shannon Seitz, and Jeffrey Smith. 2003. "Equilibrium Policy Experiments and the Evaluation of Social Programs”. Queen’s University Working Paper 1012.

Loeb, Susanna. 2001. "Estimating the Effects of a School Finance Reform: A Framework for a Federalist System”. Journal of Public Economics, 80: 225-247.

Lumsdaine, Robin, James Stock, and David Wise. 1994. "Pension Plan Provisions and Retirement: Men and Women, Medicare, and Models". In Studies in the Economics of Aging, ed. David Wise, 183-212. Chicago, IL: University of Chicago Press.

McFadden, Daniel, and Antti P. Talvitie and Associates. 1997. "Validation of Disaggregate Travel Demand Models: Some Tests”. In Urban Demand Forecasting Project, Final Report: Volume V: Demand Model Estimation and Validation. Part II, Chapter 3. Berkeley: Institute of Transportation Studies, University of California, Berkeley.

McMillan, Robert. 2000. "Parental Involvement and Competition: An Empirical Analysis of Public School Quality”. University of Toronto Working paper.

Murray, Sheila, William Evans, and Robert Schwab. 1998. "Education Finance Reform and the Distribution of Education Resources”. American Economic Review, 88: 789-812.

Nechyba, Thomas. 2004. "Prospects for Achieving Equity or Adequacy in Education: The Limits of State Aid in General Equilibrium". In Helping Children Left Behind: State Aid and the Pursuit of Educational Equity, ed. John Yinger, 111-143. Cambridge, MA: MIT Press.

Nechyba, Thomas. 1999. "School Financed Induced Migration Patterns: The Case of Private School Vouchers”. Journal of Public Economic Theory, 1(1): 5-50.

Papke, Leslie. 2005. The Effects of Spending on Test Pass Rates: Evidence From Michigan. Journal of Public Economics, 89(5-6): 821-839.

Roy, Joydeep. 2003. Impact of School Finance Reform on Resource Equalization and Academic Performance: Evidence From Michigan. Princeton University Working Paper.

Roy, Joydeep. 2004. Effect of a School Finance Reform on Housing Variables and Socieconomic Segregation: Evidence from Michigan. Princeton University Working Paper.

Sieg, Holger, Kerry Smith, Spencer Banzhaf, and Randall Walsh. 2004 "Estimating the General Equilibrium Benefits of Large Changes in Spatially Delineated Public Goods". International Economic Review, 45(4): 1047-1077.

Todd, Petra and Kenneth I. Wolpin. 2006. "Assessing the Impact of a School Subsidiy Program in Mexico: Using a Social Experiment to Validate a Dynamic Behavioral Model of Child Schooling and Fertility”. American Economic Review, 96(5): 1384-1417. 
TABLE 1

Parameter Estimates

\begin{tabular}{c|c}
\hline Parameter & Estimates \\
\hline$\alpha$ & $0.137(0.003)$ \\
$\beta$ & $0.740(0.003)$ \\
$\rho$ & $0.871(0.002)$ \\
$b$ & $0.006(0.001)$ \\
\hline Sum of Squared Residuals & 569.669 \\
\hline
\end{tabular}

Standard Errors in parentheses. Number of observations: 83 school districts.

TABLE 2

In-Sample Goodness of Fit: Some Correlations

a. Observed Data

\begin{tabular}{l|cccc}
\hline & Income & Rental Value & Spending & School Quality \\
\cline { 2 - 5 } Income & 1 & & & \\
Rental Value & 0.99 & 1 & & \\
Spending & 0.66 & 0.65 & 1 & 1 \\
School Quality & 0.85 & 0.86 & 0.59 & \\
\hline \multicolumn{5}{c}{ b. Fitted Data } \\
Income & Income & Rental Value & Spending & School Quality \\
\cline { 2 - 5 } Rental Value & 1 & 1 & & \\
Spending & 0.98 & 0.44 & 1 & \\
School Quality & 0.46 & 0.98 & 0.54 & 1 \\
\hline
\end{tabular}

Number of observations: 83 districts. Data in Tables 2-5 refer to district averages, and correlations are weighted by district number of housing units.

TABLE 3

Out-of-Sample Goodness of Fit: Some Correlations

a. Observed Data

\begin{tabular}{l|cccc}
\hline & Income & Rental Value & $\begin{array}{c}\text { Foundation } \\
\text { Allowance }\end{array}$ & $\begin{array}{c}\text { School } \\
\text { Quality }\end{array}$ \\
\cline { 2 - 5 } Income & 1 & & & \\
Rental Value & 0.98 & 1 & & \\
Foundation Allowance & 0.63 & 0.61 & 1 & 1 \\
School Quality & 0.69 & 0.70 & 0.46 & 16 \\
\hline
\end{tabular}

b. Fitted Data

\begin{tabular}{l|ccccc}
\hline & Income & Rental Value & $\begin{array}{c}\text { Foundation } \\
\text { Allowance }\end{array}$ & Spending & $\begin{array}{c}\text { School } \\
\text { Quality }\end{array}$ \\
\cline { 2 - 6 } Income & 1 & & & & \\
Rental Value & 0.99 & 1 & & & \\
Foundation Allowance & 0.38 & 0.38 & 1 & 1 & \\
Spending & 0.41 & 0.41 & 0.97 & 0.45 & 1 \\
School Quality & 0.99 & 0.99 & 0.43 & & \\
\hline
\end{tabular}


TABLE 4

Out-Of-Sample Goodness of Fit: Correlation between Observed and Predicted Changes

\begin{tabular}{|cccc}
\hline Income & Rental Value & Revenue & School Quality \\
\hline 0.39 & 0.46 & 0.60 & 0.59 \\
\hline
\end{tabular}

Number of observations: 83 districts. Data refer to the correlation between district predicted and observed change in the corresponding average.

TABLE 5

Out-Of-Sample Goodness of Fit: Correlations Between 1990 Values and Percent Changes

\begin{tabular}{l|cccc}
\hline & Income & Rental Value & Revenue & School Quality \\
\hline Observed Data & -0.23 & -0.63 & -0.72 & -0.83 \\
Fitted Data & -0.26 & -0.72 & -0.76 & -0.79 \\
\hline
\end{tabular}

Number of observations: 83 districts. Data refer to district averages and percent change in district averages. For instance, -0.23 under "Income" for the observed data means that the correlation between 1990 observed income and the percent income change over the decade is -0.23 , and -0.26 under "Income" for the fitted data means that the correlation between 1990 predicted income and the predicted percent change is -0.26 .

TABLE 6

Out-of-Sample Goodness of Fit: Correlations between Changes

a. Observed Data

\begin{tabular}{l|cccccc}
\hline & Income & $\begin{array}{c}\text { Rental } \\
\text { Value }\end{array}$ & Spending & $\begin{array}{c}\text { School } \\
\text { Quality }\end{array}$ & $\begin{array}{c}\text { Housing } \\
\text { Quality }\end{array}$ & $\begin{array}{c}\text { Relative } \\
\text { Size }\end{array}$ \\
\cline { 2 - 7 } Income & 1 & & & & & \\
Rental Value & 0.49 & 1 & & & & \\
Spending & 0.13 & 0.27 & 1 & & & \\
School Quality & 0.22 & 0.59 & 0.20 & 1 & & \\
Housing & 0.35 & 0.20 & 0.26 & 0.05 & & \\
$\quad$ Quality & & & & & & \\
Relative Size & -0.35 & -0.72 & -0.03 & -0.73 & 0.05 & 1 \\
\hline
\end{tabular}

\section{b. Fitted Data}

\begin{tabular}{l|cccccc}
\hline & Income & $\begin{array}{c}\text { Rental } \\
\text { Value }\end{array}$ & Spending & $\begin{array}{c}\text { School } \\
\text { Quality }\end{array}$ & $\begin{array}{c}\text { Housing } \\
\text { Quality }\end{array}$ & $\begin{array}{c}\text { Relative } \\
\text { Size }\end{array}$ \\
\cline { 2 - 7 } Income & 1 & & & & & \\
Rental Value & 0.75 & 1 & & & & \\
Spending & 0.47 & 0.40 & 1 & 1 & & \\
School Quality & 0.67 & 0.96 & 0.50 & 0.09 & 1 & \\
Housing & 0.48 & 0.25 & 0.27 & 0.05 & 1 \\
$\quad$ Quality & & & & & & \\
Relative Size & -0.17 & -0.67 & 0.21 & -0.56 & 0.05 & \\
\hline
\end{tabular}

Number of observations: 83 districts. Data refer to percent change in district average for income, rental value, spending, school quality and housing quality, and change for district relative size. Correlations are weighted by district number of housing units. 
TABLE 7

Effects of Alternative Policies

a. Revenue per Student

\begin{tabular}{c|cccccc}
\hline & $\begin{array}{c}\text { DPE } \\
(1)\end{array}$ & $\begin{array}{c}\text { Proposal A } \\
(2)\end{array}$ & $\begin{array}{c}\text { Tax Reform } \\
(3)\end{array}$ & $\begin{array}{c}\text { Adjusted DPE } \\
(4)\end{array}$ & $\begin{array}{c}\text { Low Foundation } \\
(5)\end{array}$ & $\begin{array}{c}\text { High Foundation } \\
(6)\end{array}$ \\
\hline Average Revenue & $\$ 5,700$ & $\$ 6,400$ & $\$ 5,700$ & $\$ 6,100$ & $\$ 6,100$ & $\$ 14,900$ \\
$\quad$ Urban Districts & $\$ 3,600$ & $\$ 5,700$ & $\$ 3,600$ & $\$ 4,500$ & $\$ 6,100$ & $\$ 14,900$ \\
$\quad$ Suburban Districts & $\$ 6,400$ & $\$ 6,700$ & $\$ 6,400$ & $\$ 6,600$ & $\$ 6,100$ & $\$ 14,900$ \\
$\quad$ High-income Districts & $\$ 10,100$ & $\$ 8,200$ & $\$ 1,000$ & $\$ 10,100$ & $\$ 6,100$ & $\$ 14,900$ \\
Highest / Lowest & 10.06 & 2.30 & 10.06 & 7.51 & 1.00 & 1.00 \\
$75^{\text {th }}$ percentile / 25 $5^{\text {th }}$ percentile & 2.21 & 1.26 & 2.21 & 1.84 & 1.00 & 1.00 \\
Avg. Proportional Change & & 0.34 & 0.00 & 0.10 & 0.35 & 2.28 \\
$\quad$ Urban Districts & & 0.58 & 0.00 & 0.26 & 0.69 & 3.14 \\
$\quad$ Suburban Districts & & 0.26 & 0.00 & 0.05 & 0.24 & 2.02 \\
$\quad$ High-income Districts & & -0.18 & 0.00 & 0.00 & -0.38 & 0.52 \\
\hline
\end{tabular}

b. Household Income

\begin{tabular}{l|cccccc}
\hline & $\begin{array}{c}\text { DPE } \\
(1)\end{array}$ & $\begin{array}{c}\text { Proposal A } \\
(2)\end{array}$ & $\begin{array}{c}\text { Tax Reform } \\
(3)\end{array}$ & $\begin{array}{c}\text { Adjusted DPE } \\
(4)\end{array}$ & $\begin{array}{c}\text { Low Foundation } \\
(5)\end{array}$ & $\begin{array}{c}\text { High Foundation } \\
(6)\end{array}$ \\
\hline Average Household Income & $\$ 66,700$ & $\$ 66,700$ & $\$ 66,700$ & $\$ 66,700$ & $\$ 66,700$ & $\$ 66,700$ \\
$\quad$ Urban Districts & $\$ 26,700$ & $\$ 26,900$ & $\$ 26,900$ & $\$ 26,700$ & $\$ 27,100$ & $\$ 27,000$ \\
Suburban Districts & $\$ 79,100$ & $\$ 79,100$ & $\$ 79,100$ & $\$ 79,100$ & $\$ 79,000$ & $\$ 79,000$ \\
$\quad$ High-income Districts & $\$ 94,100$ & $\$ 91,000$ & $\$ 93,800$ & $\$ 93,400$ & $\$ 88,300$ & $\$ 88,300$ \\
Highest / Lowest & 8.40 & 8.40 & 8.40 & 8.40 & 8.40 & 8.40 \\
$75^{\text {th }}$ percentile / 25 ${ }^{\text {th }}$ percentile & 2.54 & 2.42 & 2.53 & 2.50 & 2.34 & 2.34 \\
Avg. Proportional Change & & 0.00 & 0.00 & 0.00 & 0.00 & 0.00 \\
$\quad$ Urban Districts & & 0.01 & 0.01 & 0.00 & 0.01 & 0.01 \\
$\quad$ Suburban Districts & & 0.00 & 0.00 & 0.00 & 0.00 & 0.00 \\
$\quad$ High-income Districts & & -0.04 & 0.00 & -0.01 & -0.08 & -0.08 \\
\hline
\end{tabular}




\section{c. Rental Value}

\begin{tabular}{|c|c|c|c|c|c|c|}
\hline & $\begin{array}{l}\mathrm{DPE} \\
(1)\end{array}$ & $\begin{array}{c}\text { Proposal A } \\
(2)\end{array}$ & $\begin{array}{c}\text { Tax Reform } \\
\text { (3) }\end{array}$ & $\begin{array}{c}\text { Adjusted DPE } \\
\text { (4) }\end{array}$ & $\begin{array}{c}\text { Low Foundation } \\
\text { (5) }\end{array}$ & $\begin{array}{c}\text { High Foundation } \\
\text { (6) }\end{array}$ \\
\hline Average Rental Value & $\$ 21,500$ & $\$ 21,900$ & $\$ 22,300$ & $\$ 21,300$ & $\$ 21,800$ & $\$ 21,100$ \\
\hline Urban Districts & $\$ 12,100$ & $\$ 12,400$ & $\$ 12,600$ & $\$ 12,100$ & $\$ 12,400$ & $\$ 12,300$ \\
\hline Suburban Districts & $\$ 24,400$ & $\$ 24,800$ & $\$ 25,300$ & $\$ 24,200$ & $\$ 24,700$ & $\$ 23,900$ \\
\hline High-income Districts & $\$ 28,200$ & $\$ 27,800$ & $\$ 28,700$ & $\$ 27,800$ & $\$ 26,900$ & $\$ 26,000$ \\
\hline Highest / Lowest & 4.49 & 4.48 & 4.57 & 4.46 & 4.45 & 4.27 \\
\hline $75^{\text {th }}$ percentile $/ 25^{\text {th }}$ percentile & 2.05 & 1.97 & 2.00 & 2.02 & 1.91 & 1.88 \\
\hline Avg. Proportional Change & & 0.02 & 0.04 & -0.01 & 0.02 & -0.01 \\
\hline Urban Districts & & 0.03 & 0.04 & 0.00 & 0.03 & 0.02 \\
\hline Suburban Districts & & 0.02 & 0.03 & -0.01 & 0.01 & -0.02 \\
\hline High-income Districts & & -0.02 & 0.02 & 0.00 & -0.05 & -0.08 \\
\hline
\end{tabular}

\section{d. School Quality}

\begin{tabular}{|c|c|c|c|c|c|c|}
\hline & $\begin{array}{c}\mathrm{DPE} \\
(1) \\
\end{array}$ & $\begin{array}{c}\text { Proposal A } \\
\text { (2) }\end{array}$ & $\begin{array}{c}\text { Tax Reform } \\
\text { (3) }\end{array}$ & $\begin{array}{c}\text { Adjusted DPE } \\
(4)\end{array}$ & $\begin{array}{c}\text { Low Foundation } \\
\text { (5) }\end{array}$ & $\begin{array}{c}\text { High Foundation } \\
(6) \\
\end{array}$ \\
\hline Average School Quality & 0.50 & 0.52 & 0.51 & 0.51 & 0.54 & 0.54 \\
\hline Urban Districts & 0.22 & 0.23 & 0.22 & 0.22 & 0.25 & 0.25 \\
\hline Suburban Districts & 0.59 & 0.60 & 0.60 & 0.60 & 0.63 & 0.63 \\
\hline High-income Districts & 0.73 & 0.70 & 0.73 & 0.73 & 0.70 & 0.70 \\
\hline Ratio of Highest To Lowest & 8.21 & 6.81 & 8.20 & 7.89 & 6.38 & 6.38 \\
\hline $75^{\text {th }}$ percentile $/ 25^{\text {th }}$ percentile & 2.27 & 2.22 & 2.26 & 2.25 & 2.10 & 2.10 \\
\hline Avg. Proportional Change & & 0.05 & 0.00 & 0.01 & 0.11 & 0.11 \\
\hline Urban Districts & & 0.08 & 0.01 & 0.03 & 0.16 & 0.16 \\
\hline Suburban Districts & & 0.04 & 0.00 & 0.01 & 0.09 & 0.09 \\
\hline High-income Districts & & -0.04 & 0.00 & -0.01 & -0.06 & -0.06 \\
\hline
\end{tabular}


e. Fiscal Implications

\begin{tabular}{l|lllllc}
\hline & \multicolumn{1}{|c}{$\begin{array}{c}\text { DPE } \\
(1)\end{array}$} & $\begin{array}{c}\text { Proposal A } \\
(2)\end{array}$ & $\begin{array}{c}\text { Tax Reform } \\
(3)\end{array}$ & $\begin{array}{c}\text { Adjusted DPE } \\
(4)\end{array}$ & $\begin{array}{c}\text { Low Foundation } \\
(5)\end{array}$ & $\begin{array}{c}\text { High Foundation } \\
(6)\end{array}$ \\
\hline Residential Property Tax Rate & & & & & & \\
$\quad$ Average & 0.07 & 0.02 & 0.03 & 0.07 & 0.02 & 0.02 \\
$\quad$ Minimum & 0.04 & 0.02 & 0.02 & 0.04 & 0.02 & 0.02 \\
$\quad$ Maximum & 0.09 & 0.06 & 0.10 & 0.09 & 0.02 & 0.02 \\
Non-residential Property Tax Rate & & & & & \\
$\quad$ Average & 0.07 & 0.10 & 0.10 & 0.07 & 0.10 & 0.10 \\
$\quad$ Minimum & 0.04 & 0.10 & 0.10 & 0.04 & 0.10 & 0.10 \\
$\quad$ Maximum & 0.09 & 0.10 & 0.10 & 0.08 & 0.10 & 0.10 \\
Income Tax Rate & 0.00 & 0.02 & 0.01 & 0.00 & 0.02 & 0.07 \\
Avg. Tax Burden per Household & $\$ 1,700$ & $\$ 1,800$ & $\$ 1,400$ & $\$ 1,800$ & $\$ 1,600$ & $\$ 5,000$ \\
Avg. Net Income Tax Subsidy per Student & $\$ 0$ & $\$ 0$ & $\$ 0$ & $\$ 0$ & $\$ 0$ & $\$ 0$ \\
$\quad$ High-income Districts & $-\$ 500$ & $-\$ 4,000$ & $-\$ 2,600$ & $-\$ 1,100$ & $-\$ 5,100$ & $-\$ 11,100$ \\
$\quad$ Low-income Districts & $\$ 100$ & $\$ 1,100$ & $\$ 700$ & $\$ 300$ & $\$ 1,400$ & $\$ 3,100$ \\
Avg. Share of Residential Property Taxes & 0.69 & 0.21 & 0.30 & 0.64 & 0.22 & 0.09 \\
Avg. Share of Non-Residential Property Taxes & 0.22 & 0.26 & 0.31 & 0.21 & 0.30 & 0.12 \\
Avg. Share of Income Taxes & 0.09 & 0.53 & 0.39 & 0.15 & 0.48 & 0.79 \\
\hline
\end{tabular}

Number of observations: 83 districts. For a given variable, "Highest/Lowest" is the ratio of the metropolitan area's highest to lowest district average, "75 percentile $/ 25^{\text {th }}$ percentile" is the ratio of the metropolitan area's $75^{\text {th }}$ to $25^{\text {th }}$ percentile, and "average proportional change" is the average of the proportional change in district averages. Dollar figures rounded to closest hundred. All averages are weighted; weight is number of housing units. 
FIGURE 1

Detroit Metropolitan Area in 1990

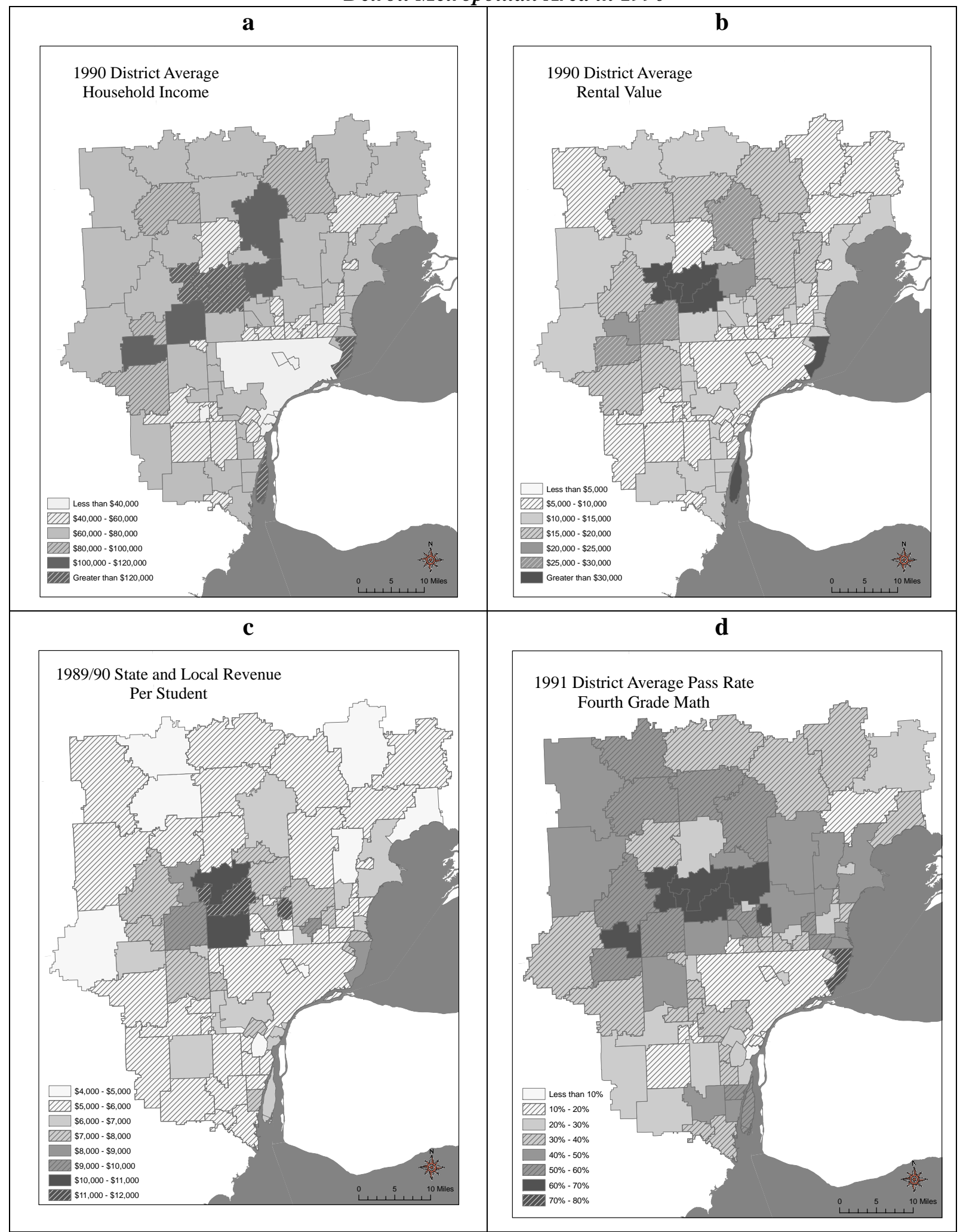

Source: 1990 School District Data Book, Michigan Department of Treasury, and Michigan Department of Education. 
FIGURE 2

\section{Real Foundation Allowance and 1993 Base Revenue Detroit Metropolitan Area}

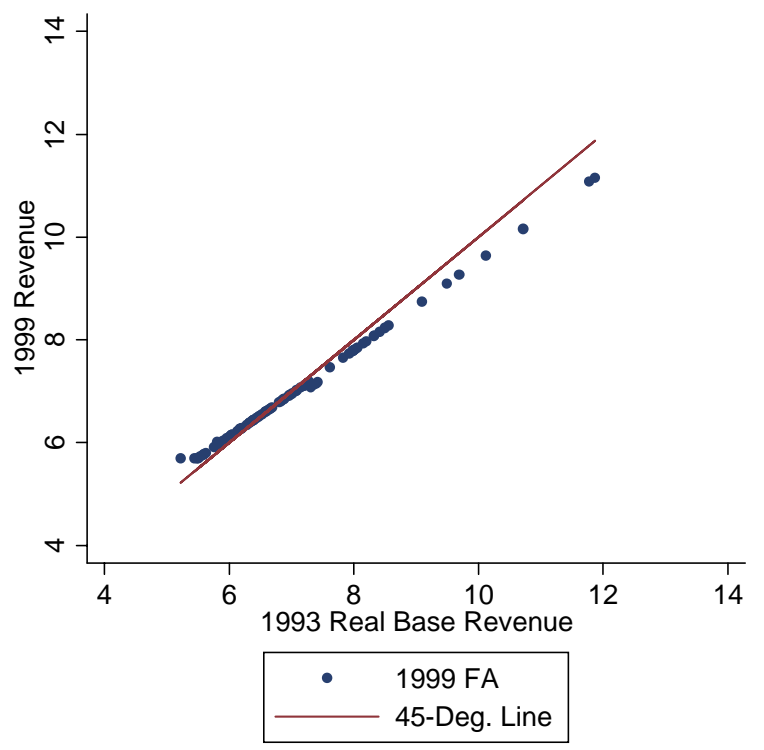

FA: Foundation Allowance. Revenue and foundation allowance expressed in thousands of 2000 dollars. Source: Michigan Bulletin 1014.

FIGURE 3

Districts, Neighborhoods and 1990 Housing Quality in the Detroit Metropolitan Area

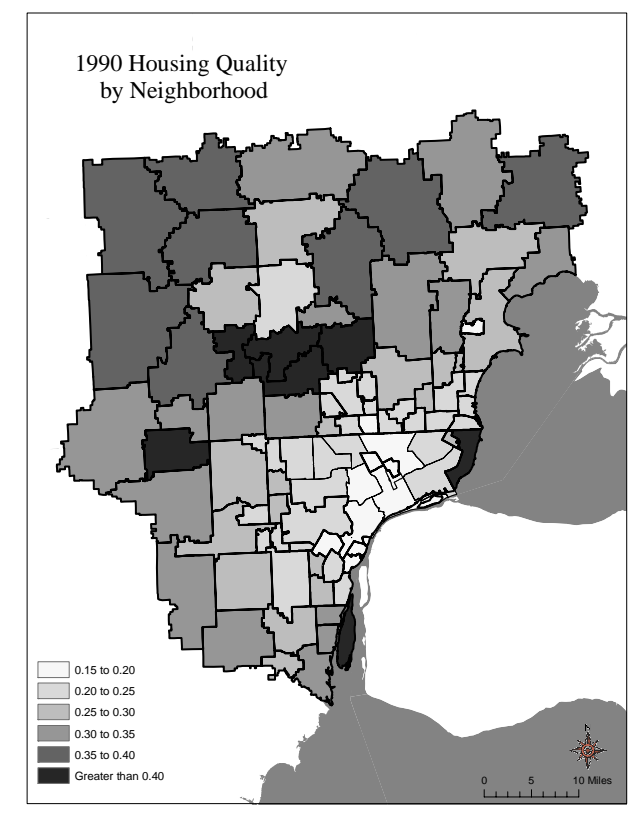

The thicker black lines represent school district boundaries, and the thin lines represent neighborhood boundaries. Source: author's calculations using 1990 Census data. 


\section{FIGURE 4}

\section{Changes in the Detroit Metropolitan Area}

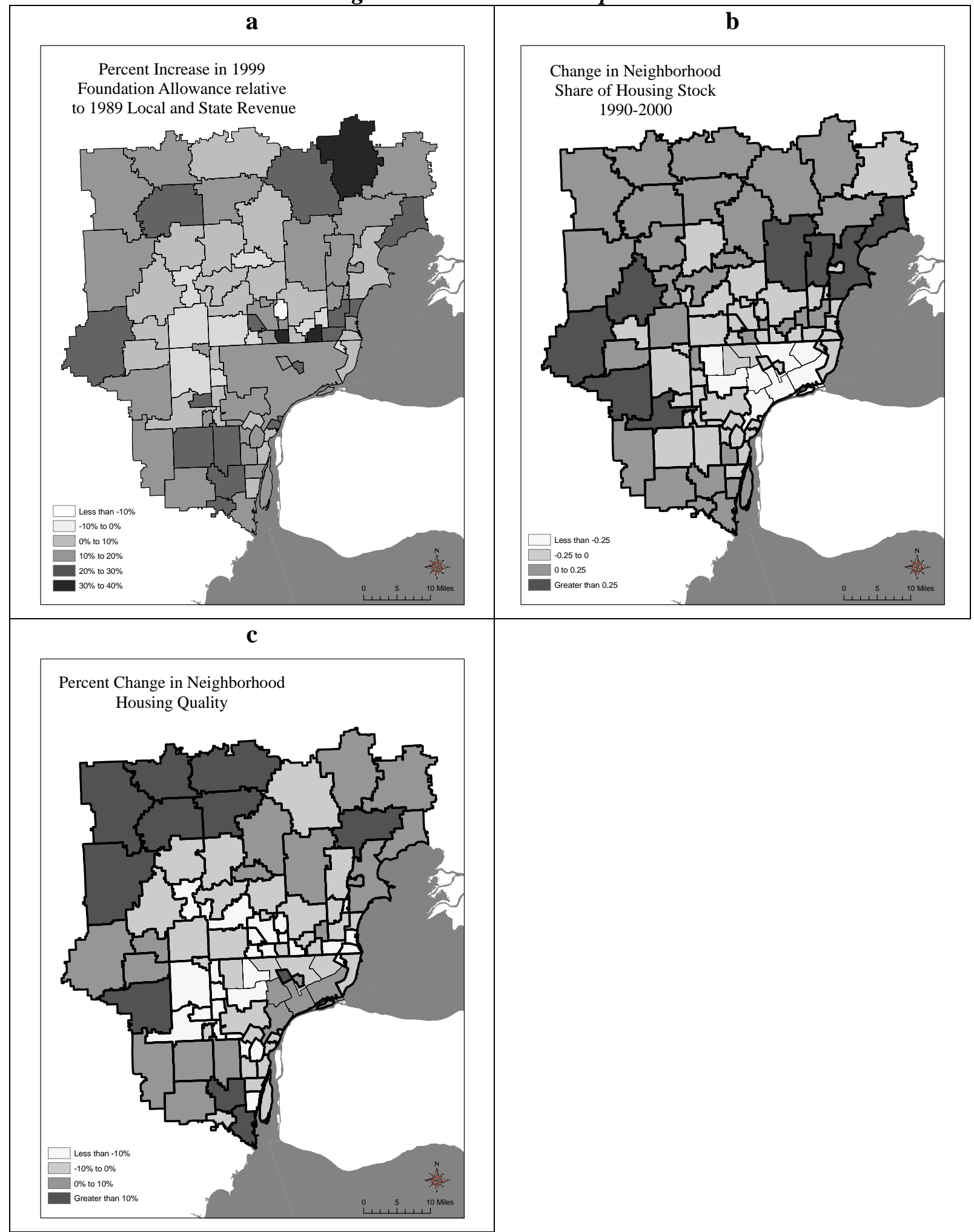

Source: Michigan Department of Treasury, School District Data Book, and author's own calculations based on 1990 and 2000 Census. 
FIGURE 5

In-Sample Goodness of Fit: Fitted vs. Observed Values

Figure 5a - Average Household Income (in $\$ 10,000$ )

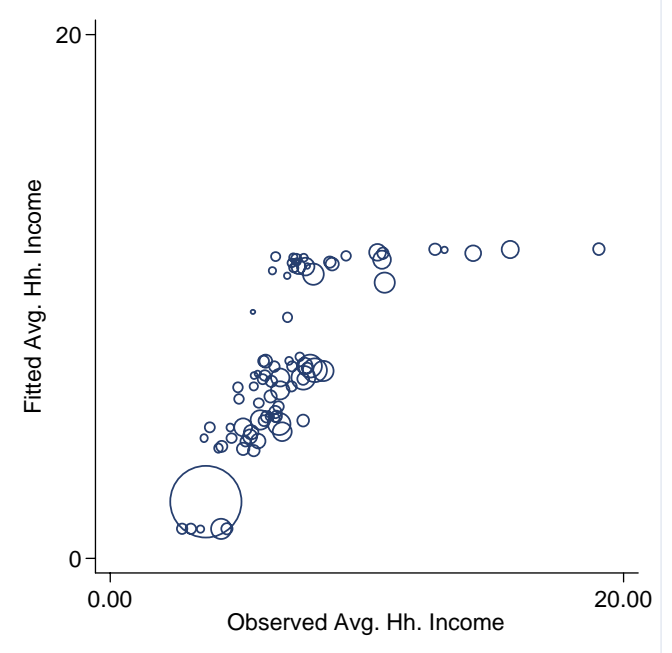

Figure 5c - Spending per Student in Public Schools (in $\$ 10,000$ )

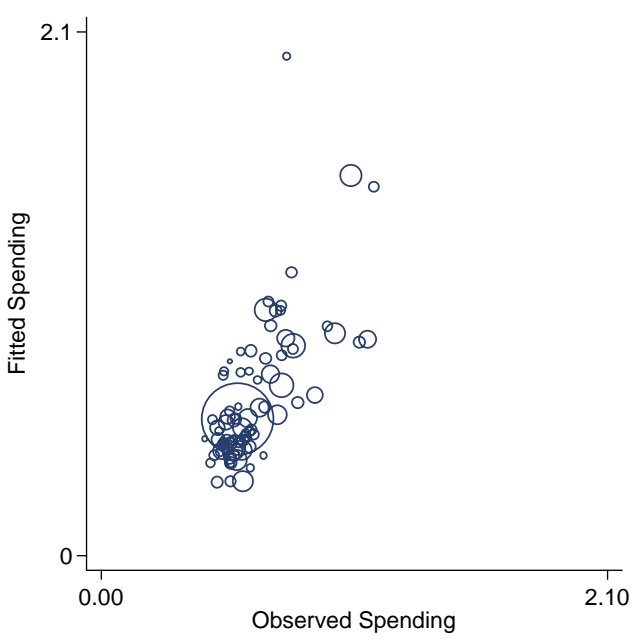

Figure 5b - Average Rental Value (in $\$ 10,000$ )

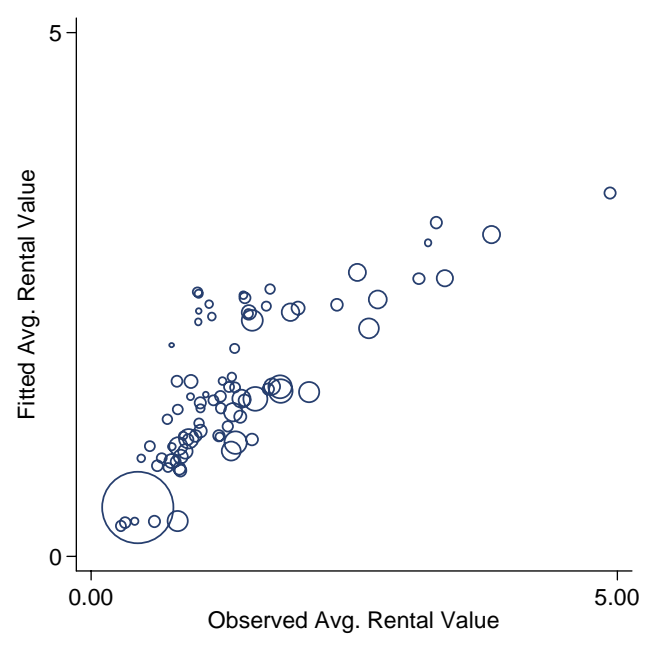

Figure 5d - Public School Quality

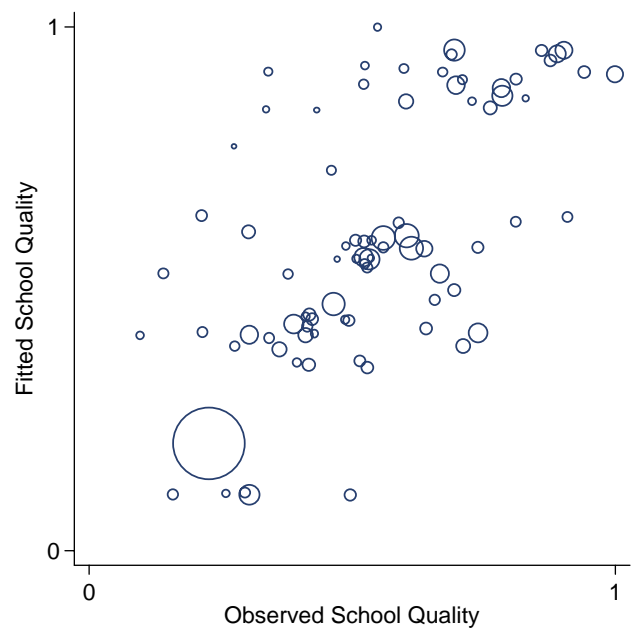

Note: observed values on the horizontal axis; fitted values on the vertical axis. Circle size is proportional to the observation's total measure of households. Correlations between fitted and observed values are weighted by the observations' measure of households and are as follows: 0.84, 0.88, 0.76, and 0.83 for Figs. 5a through 5d respectively. 
FIGURE 6 - Out-Of-Sample Goodness of Fit: Fitted vs. Observed Values

Figure 6a - Average Household Income

(in $\$ 10,000$ )

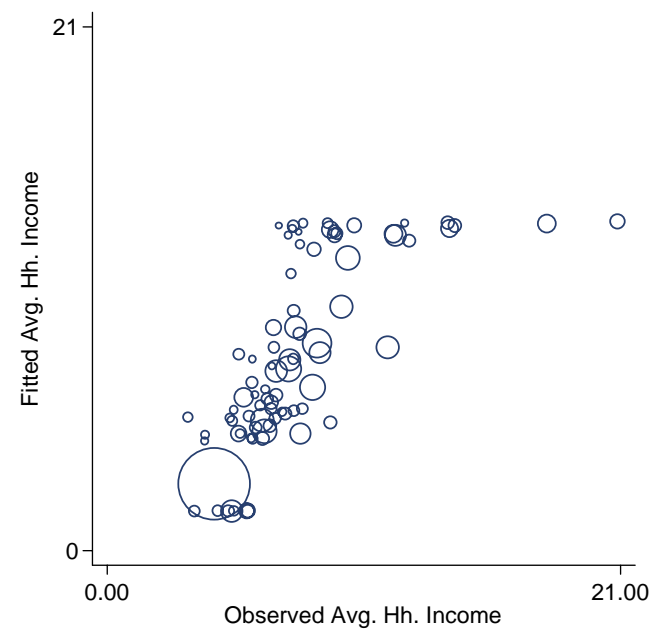

Figure 6c - Foundation Allowance (in $\$ 10,000$ )

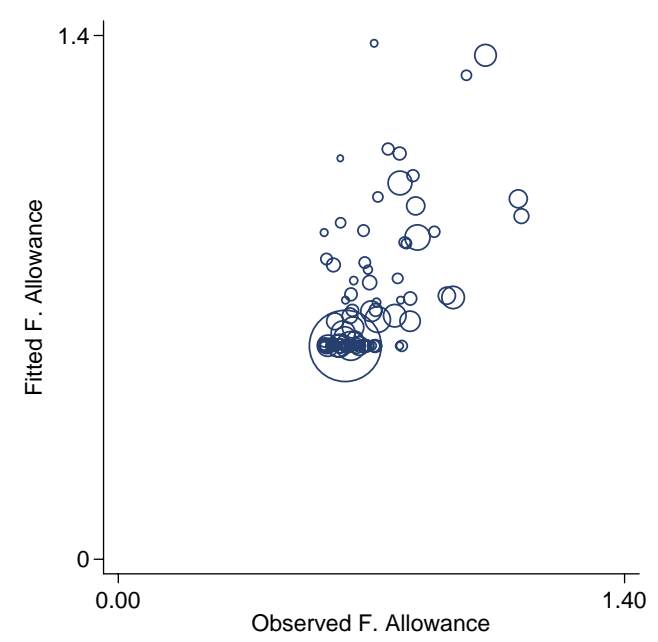

Figure 6b - Average Rental Value

(in $\$ 10,000$ )

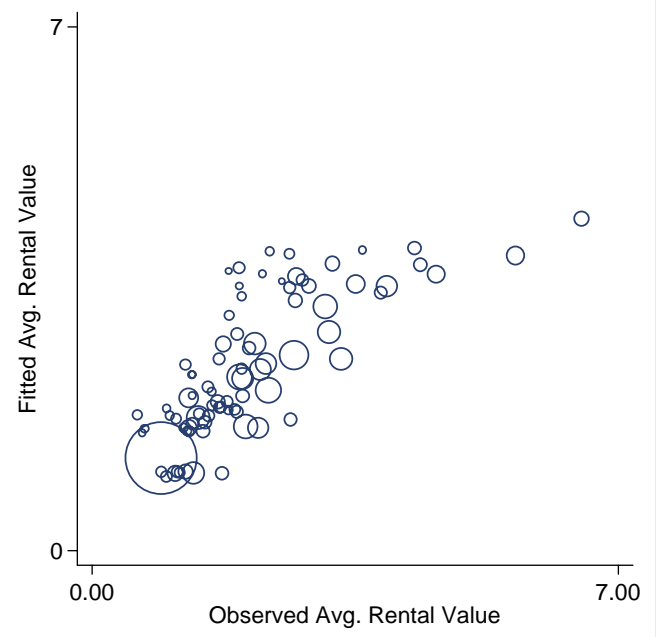

Figure 6d - Per-Pupil Spending (in $\$ 10,000$ )

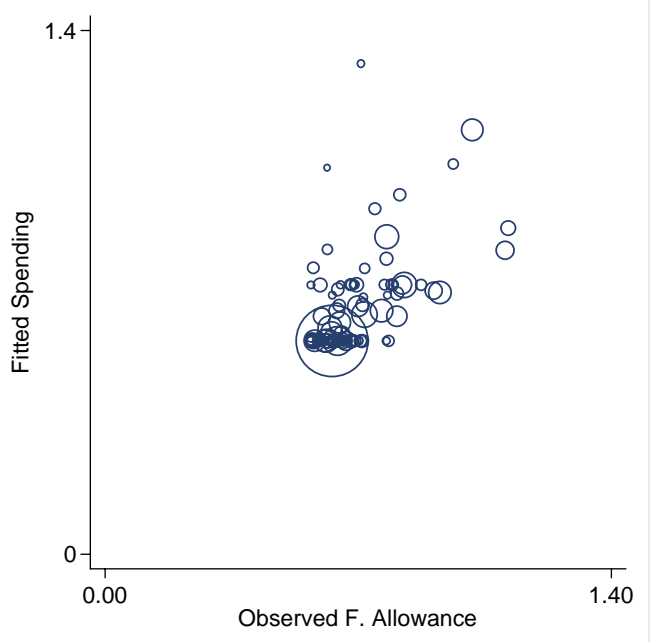

Figure 6e - Public School Quality

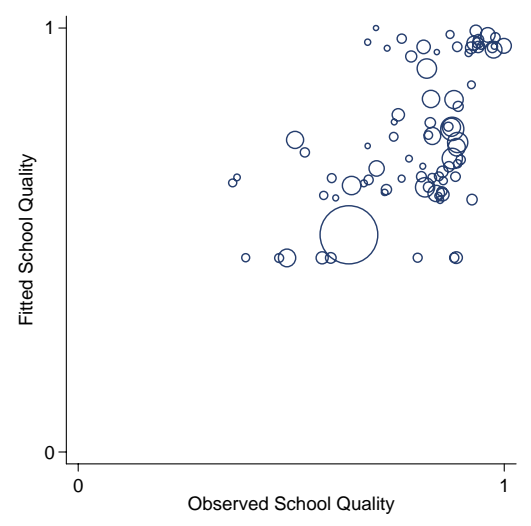

Note: see Figure 5. Correlations between fitted and observed values are weighted by the observations' measure of households and are as follows: .82, .86, .71 .71, .69 for Figs. 6a through 6e respectively. 